\title{
Study of a Sea-Breeze Case through Momentum, Temperature, and Turbulence Budgets*
}

\author{
J. CUXART \\ University of the Balearic Islands, Palma de Mallorca, Spain \\ M. A. JIMÉNEZ \\ Mediterranean Institute for Advanced Studies (IMEDEA), Esporles, Spain \\ M. Telišman PRTEnJAK AND B. GRISOgONO \\ Faculty of Sciences, University of Zagreb, Zagreb, Croatia
}

(Manuscript received 11 December 2013, in final form 29 July 2014)

\begin{abstract}
A simulation with the Méso-NH model over the island of Mallorca, Spain, has been made in a case of synoptic high pressure (5 June 2010) that allowed the development of sea breezes (SB) in the three main basins of the island. The results compare well to the available observations and are qualitatively very close to a previous idealized study with no synoptic forcing made by Ramis and Romero in 1995. The temporal and spatial structure of the SB in the southeastern basin is analyzed with the use of the momentum, temperature, and turbulence kinetic energy budgets provided by the numerical model. Five stages of evolution from before dawn to after sunset are discussed, identifying the main physical mechanisms at play. The morning land heating warms the land and the air over it until an air temperature gradient is created and a marine flow accelerates inland, dragged by turbulence in the low layers. The upper part of the inland current and the layers just above are dominated by compensatory motions, which oppose the corresponding pressure gradient at these levels. These mechanisms last while the SB is active, with significant effects from the local topography, and they decrease in intensity as sunset approaches. This relatively simple case has been used to check the goodness of two analytical models of the SB that perform relatively well because they use turbulence as a surrogate for the missing advection terms in the layers above $200 \mathrm{~m}$. These models are formulated here in a more consistent manner in the turbulence parameterization than were the original propositions.
\end{abstract}

\section{Introduction}

The sea/land breeze $(\mathrm{SB} / \mathrm{LB})$ is a phenomenon that can be found in coastal zones in almost every latitude of Earth, from the tropics (e.g., Qian et al. 2012) to the polar regions (e.g., Kozo 1982), and research on the subject has been intense for temperate latitudes (e.g., Miller et al. 2003; Crosman and Horel 2010). The necessary condition is that the air over the land is able to

\footnotetext{
* Supplemental information related to this paper is available at the Journals Online website: http://dx.doi.org/10.1175/JAMC-D-14-0007.s1.

Corresponding author address: J. Cuxart, Faculty of Sciences, University of the Balearic Islands, Carret. Valldemossa km 7.5, 07122 Palma de Mallorca, Illes Balears, Spain.

E-mail: joan.cuxart@uib.cat
}

reach, by radiative solar heating of the surface, temperatures that are higher than those of the air over the neighboring sea surface in a situation in which the general winds are weak.

The impact of SB on human activities is large. According to the online United Nations Atlas of the Oceans (http://www.oceansatlas.org), 8 of the 10 largest cities of the world are located by the coast, with higher rates of growth than other areas, and $44 \%$ of the world population lives within $150 \mathrm{~km}$ of the sea. Therefore, SB investigations over the past decades have been long-term and extensive. Besides the analytical approaches and the simplifications that they imply, such as in Defant (1950) and Rotunno (1983) or recently in Drobinski et al. (2011) and Jiang (2012), observational and numerical studies have been done. The SB system has been examined through statistical analyses and field experiments, such as those by 
Holland and McBride (1989), Finkele et al. (1995), and Azorin-Molina et al. (2009), as well as through laboratory experiments like the one by Simpson and Britter (1980). Complementary insight has been given by extensive numerical modeling, as reviewed in Crosman and Horel (2010). Investigations of the 3D nonhydrostatic simulations that consider detailed land-cover characteristics and soil moisture on the SB in real synoptic conditions are still rare (Kala et al. 2010), with some different results and conclusions.

From the 1990s onward, large-eddy simulations (LES) have provided analyses of the finescale SB structure and its interaction with the atmospheric boundary layer (ABL) features. The degree of success of those simulations (especially in the earlier works) was dependent on the available computational capabilities (Crosman and Horel 2010), however. Antonelli and Rotunno (2007) recently performed an LES of the onset of the idealized SB. They varied the land surface sensible heat flux $H$ (as invariant in time), the initial atmospheric stability, and the Coriolis parameter while the effects of moisture, synoptic-scale wind, and curvature of the coast were neglected. Their work has been extended by Crosman and Horel (2012) to an idealized 3D lake-breeze investigation, in which they used a time-varying surface sensible heat flux over land (ignoring the interaction between onshore flow and ground surface temperature), zero heat flux over the water, and a straight coastline.

Robinson et al. (2013) have focused on the effects of underlying heating and background stratification on the 2D idealized dry SB over simple heated islands while not considering topography, surface roughness, rotation, initial humidity, or background wind. Therefore, despite some progress, the influence of the ABL in more real, or completely realistic, 3D conditions during the onset of SB (Crosman and Horel 2010) and daytime ABL maintenance/destruction of the SB front (Prtenjak and Grisogono 2002; Robinson et al. 2013) have not yet been fully understood.

The above-mentioned extensive work has also shown that the SB phenomenon could present different characteristics that are related to the curvature of the coastline (Miller et al. 2003) and are linked to various other meteorological features, such as slope winds (e.g., Darby et al. 2002; Prtenjak et al. 2006) or the urban heat island circulation (e.g., Savijarvi 1985; Ohashi and Kida 2002), indicating that the characteristics of the SB are dependent on the location, despite the fact that the essential mechanisms of the phenomenon seem to remain the same everywhere.

The SB over the eastern coast of the Iberian Peninsula (IP) has been analyzed in many studies (e.g., Millan et al.
1997; Kottmeier et al. 2000; Azorin-Molina et al. 2009; Fock and Schlünzen 2012; Hernández-Ceballos et al. 2013). The nearby island of Mallorca, Spain (Fig. 1), has a very large occurrence of SB, up to $70 \%-80 \%$ of the days in summer (Ramis and Romero 1995, hereinafter RR95). It is located in the western Mediterranean Sea, $200 \mathrm{~km}$ away from the Iberian coast-far enough not to be directly perturbed by the mainland IP breeze. For an isolated island, the SB is a markedly three-dimensional phenomenon that is dependent on the size of the heated land surface and thus differs from those along the IP coast. Mahrer and Segal (1985) pointed out that circular islands produce much stronger vertical velocities than does an elongated island of equal width, and Jiang (2012) showed analytically that the horizontal dimensions of SBs around an island are typically smaller than those over a straight coastline. Azorin-Molina et al. (2009) analyzed, using satellite images, differences in the lifetime and maximum intensity of the daytime convection linked to SB fronts over the IP coast and above the island of Mallorca. The differences varied significantly as a function of the background wind. Their results indicated the presence of specific SB dynamics over the island of Mallorca that have been studied so far only in a small number of studies.

In 1946 Jansà and Jaume (1946, hereinafter JJ46) described the phenomenon on the island in its mature state using information provided by the local population and produced a map of surface streamlines. Their description indicated 1) a typical SB depth of $500 \mathrm{~m}$ and the difficulty of finding a well-developed return flow above it (using balloon data), 2) the position of the convergence spots in the central area of the island, and 3) an SB duration in the range of $8-10 \mathrm{~h}$.

The first numerical simulations were made by Ramis et al. (1990) using a semi-Lagrangian one-level numerical model, followed by the mesoscale simulation of RR95, which produced idealized numerical studies of the SB with no background wind that were used later mostly for air-quality purposes (Romero and Ramis 1996). In their simulations, the daytime wind field agreed quantitatively with the findings of JJ46 and, furthermore, showed a return current over the Palma basin between 1 and $2 \mathrm{~km}$ above mean sea level (MSL). They found small-scale cyclonic eddies in the horizontal wind distributions over the island. The authors also emphasized that soil moisture was one of the most important parameters determining the timing and strength of the phenomenon.

One of the limitations in idealized SB simulations (e.g., RR95; Crosman and Horel 2012; Robinson et al. 2013) is that the SB kinetic energy is completely a result of conversion from mesoscale available potential energy 
(a)

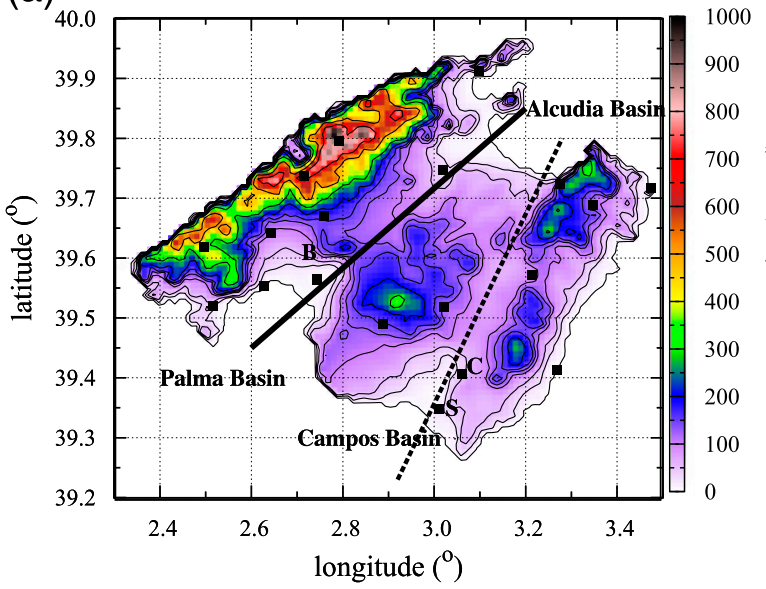

(b)

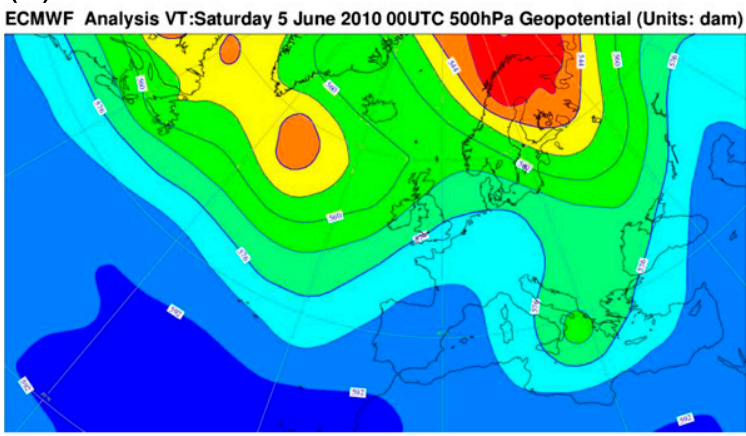

(c)

ECMWF Analysis VT:Saturday 5 June 2010 00UTC Surface: Mean sea level pressure (Units: hpa)

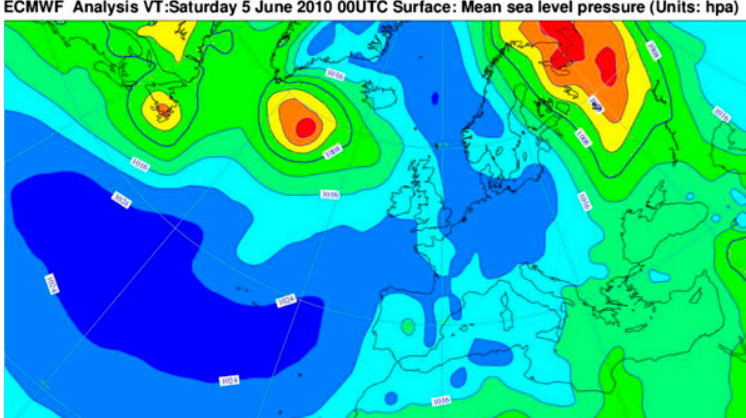

FIG. 1. (a): Topography of the island, with the locations of the AEMET surface weather stations. The straight lines indicate the vertical cross sections in Fig. 6. The surface stations of Campos and Ses Salines are labeled with the letters C and S, respectively. The location where the balloons are launched is indicated with a letter B. Also shown are the ECMWF analysis for 0000 UTC 5 Jun 2010 for (b) 500-hPa geopotential and (c) surface pressure.

as a main driving force in the system, which is established by the initial (and usually prescribed boundary) conditions. According to the SB energetics (e.g., Mahrer and Segal 1985; Prtenjak and Grisogono 2002), the SB speed quickly reaches maximum (constant) speed and the model reaches its steady state. In this work, we analyze a simulation of a real case and thus contribute to filling our partial knowledge about the SB over the island of Mallorca, which is mostly based on the idealized numerical cases. The use of high vertical resolution and detailed characterization of the land surface is expected to provide good insight on the processes near the surface. Besides, the use of analyzed large-scale winds, which could have significant effect on the SB structure (e.g., Grisogono et al. 1998; Miller et al. 2003; Steele et al. 2013; Azorin-Molina et al. 2009), may result in a more realistic representation of the $\mathrm{SB}$ evolution for this particular case.

The focus here is put on the physical processes involved through the inspection of the budgets provided by the model. Particular attention is paid to SB creation and decay, which are still not fully understood processes (Crosman and Horel 2010), and to the relationship between turbulence and the local pressure gradient in the momentum budget. As a consequence, the SB speed evolution during the surface heating process is more explicitly linked through the local pressure gradient to the turbulent behavior in this three-dimensional real case than in previous studies.

In the next section, the selected case, the model setup and diagnostics, and the basic organization of the flow are explained. Section 3 analyzes the evolution of the main terms in the budgets of temperature, momentum, and turbulence kinetic energy (TKE) for some selected columns along a line normal to the coast in the Campos basin, which leads to a description of the temporal evolution of the SB in phases in section 4. In section 5, some profiles of the simulation are used to check two different classical analytical models of the SB, and the domains of application of each one are assessed. Some conclusions are given in section 6 .

\section{Description of the case and tools}

\section{a. Location, sea-breeze characteristics, and period of interest}

The topography of the island, which has a characteristic size of $90 \mathrm{~km}$, is shown in Fig. 1. At the northwestern side, there is a continuous mountain range (Tramuntana) that generates its own system of slope winds at the western side that do not penetrate into the island. At the eastern side, there is a lower and discontinuous range (Llevant) that allows the SB to reach the center of the island. Between these two ranges, the island is fairly homogeneous (Pla de Mallorca) with a small mountain (Randa) at the south that determines the shape of the three main basins: Palma in the southwest, Campos in the southeast, and Alcúdia in the 
northeast. During the day, SBs can develop in these three basins that may interact in the central part of the island (JJ46); at night, downslope winds converge to the center of the basins, and then a flow offshore is generated (Cuxart et al. 2007).

The SB is the predominant wind regime on the island between late spring and early autumn as a result of the usual position of the archipelago under synoptic highpressure systems at this time of the year. The SB that took place on 5 June 2010 is analyzed in this work. High-pressure values (around $1020 \mathrm{hPa}$ ) with very weak general surface pressure gradients were observed in the area as part of a large Azores anticyclone (Fig. 1b). An accompanying ridge at upper levels (Fig. 1c) generated the weak large-scale flow from northern directions, with small directional changes throughout the troposphere and clear skies over the area of interest. These synoptic conditions correspond to favorable synoptic environments for SB development according to the weather-type classification (e.g., Azorin-Molina et al. 2009) used for the SB selection.

The available data are provided by the Spanish State Meteorological Agency (AEMET) and consist of a number of automatic weather stations (AWS) and the sounding in the Palma basin (Fig. 1a). In addition, the sea and land surface temperatures (SST and LST) provided by the Moderate Resolution Imaging Spectroradiometer (MODIS) sensor that is on the Aqua and Terra satellites were inspected.

We qualify this real case as "quasi ideal," because the development of the breeze circulations over the three main basins was in accord with previous knowledge and, as will be shown later, in close correspondence to the ideal study of RR95. Weak wind from the north blowing above $1000 \mathrm{~m}$ MSL breaks the symmetry in the upper layers of the ideal case. Nevertheless, a general good correspondence with RR95, the climatological study of JJ46, and traditional knowledge of the breeze on Mallorca, when compared with the actual observations of the day, indicate that it is a fairly representative case. To confirm or discard the findings presented here, however, further observational and numerical studies are necessary.

The SB time evolution is illustrated with a time series (Fig. 2) at one point near the coast (Ses Salines, labeled as $\mathrm{S}$ in Fig. 1a) and one that is $10 \mathrm{~km}$ inland (Campos, labeled as $\mathrm{C}$ in Fig. 1). Observations in the area show that the SB starts at the coast near 0800 UTC and ends close to 1900 UTC (in Mallorca, UTC and local solar times coincide). At $10 \mathrm{~km}$ inland, it arrives nearly $1 \mathrm{~h}$ later, with an average advance rate of $3 \mathrm{~m} \mathrm{~s}^{-1}$. The described duration and late-morning (fast) propagation of the undisturbed SB event appear to agree with similar SB findings along the Mediterranean coast (Bastin et al. 2005; Prtenjak et al. 2006). At Ses Salines the direction is sustainably perpendicular to the coast, whereas in Campos the direction varies since the eastcoast breeze reaches this location. The result is wind from the south-southeast direction in the central part of the day.

The entrance of the SB interrupts the morning rising of air temperature, which stays nearly constant afterward at $27^{\circ} \mathrm{C}$ close to the coast and $\sim 29^{\circ} \mathrm{C} 10 \mathrm{~km}$ inland (Fig. 2c). When the SB is set, the relative humidity drops to $35 \%-45 \%$, but with larger values at the coast (Fig. 2d). The LST of the Campos basin inland (not shown) rises in the early morning from $13^{\circ}$ to $31^{\circ} \mathrm{C}$ and then decreases to $29^{\circ} \mathrm{C}$. The SST is $21^{\circ} \mathrm{C}$ away from the island, increasing to $25^{\circ} \mathrm{C}$ close to the coast, as indicated by satellite observations.

The sounding at the Palma airport (launched at 1100 UTC; Fig. 3), located in the nearby southeasterly basin, shows that the onshore wind blows up to $6 \mathrm{~ms}^{-1}$ at a height of $160 \mathrm{~m}$ and decreases to calm up to $1400 \mathrm{~m}$ above ground level (AGL). Above that height, weak winds from the north (between 2 and $6 \mathrm{~m} \mathrm{~s}^{-1}$ ) blow during the study period up to $500 \mathrm{hPa}$, both in the day and night, and therefore we consider this to be a synoptic forcing.

\section{b. The model setup}

"Méso-NH" (Lafore et al. 1998) is a nonhydrostatic model that has been used for a large number of investigations, from LES of the idealized ABL (Cuxart et al. 2000; Jiménez and Cuxart 2005; Beare et al. 2006; Cuxart and Jiménez 2007) to the mesoscale as in some previous studies of the SB for the Mediterranean French coast (Bastin et al. 2005) and the North Sea (Talbot et al. 2007). Other uses for Mallorca or the IP have been devoted to nocturnal ABL studies in complex terrain (Cuxart et al. 2007; Jiménez et al. 2008; Martínez et al. 2010; Cuxart and Jiménez 2012).

The original physics package is currently implemented in some European weather and climate models, such as the Applications of Research to Operations at Mesoscale (AROME; Seity et al. 2011) and the High Resolution Limited Area Model (HIRLAM; Navascués et al. 2013). A summary of the chosen parameterizations is given in Table 1. It includes a TKE turbulence scheme that can be used at any horizontal resolution by switching the dimensionality of the scheme (vertical for mesoscale studies; three-dimensional for resolutions below a few hundred meters) while the formulation of the mixing length and all other parameters such as constants and thresholds is unchanged (Cuxart et al. 2000). Here, the scheme is run with 
(a)

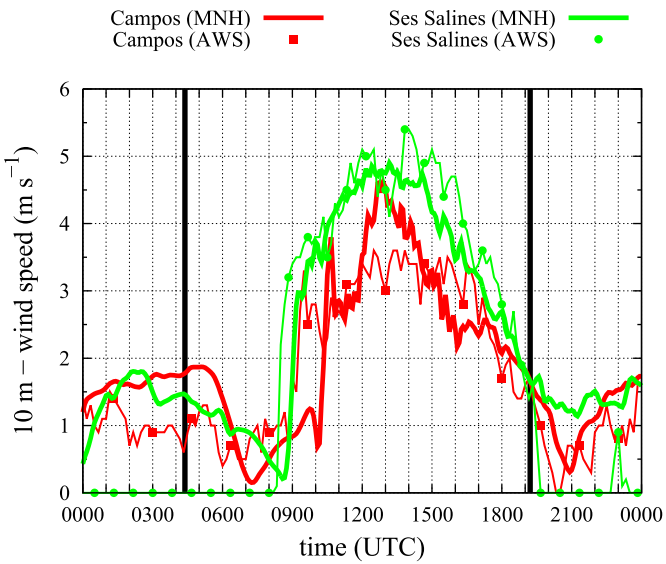

(c)

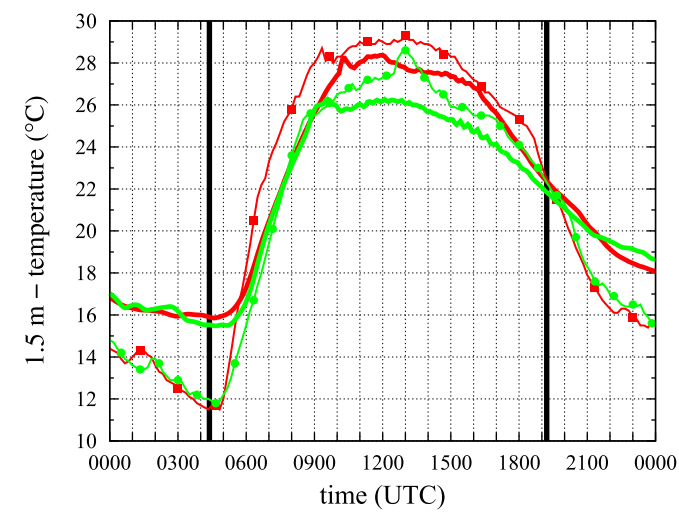

(e)

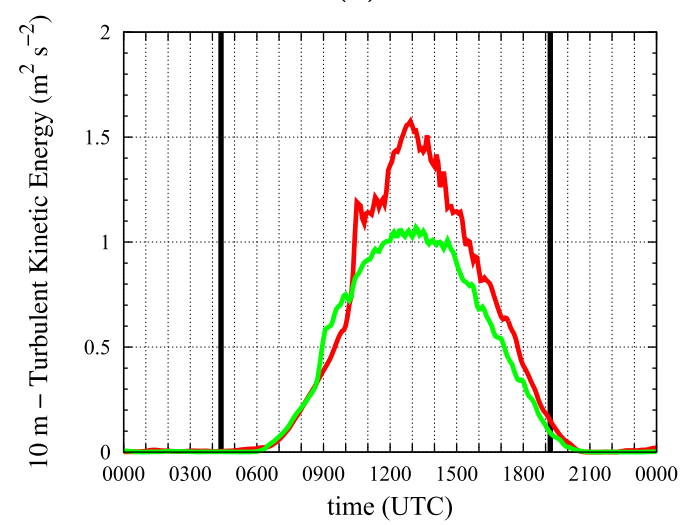

(b)

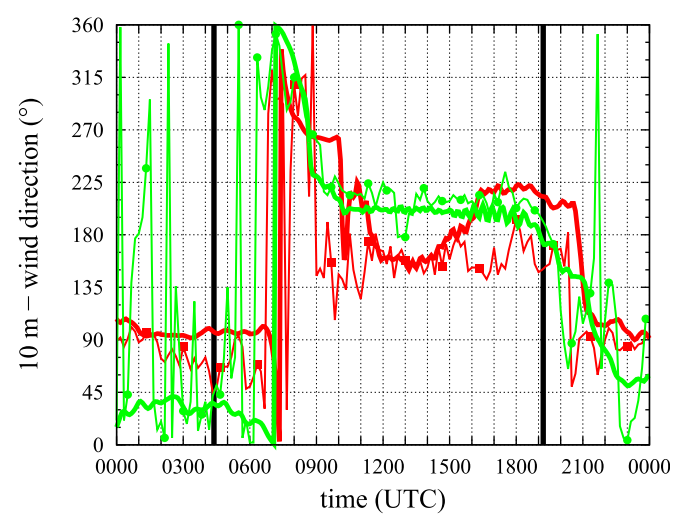

(d)

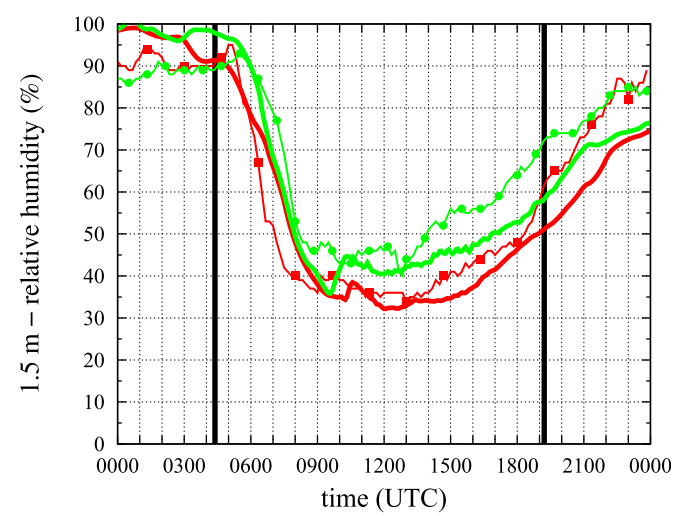

(f)

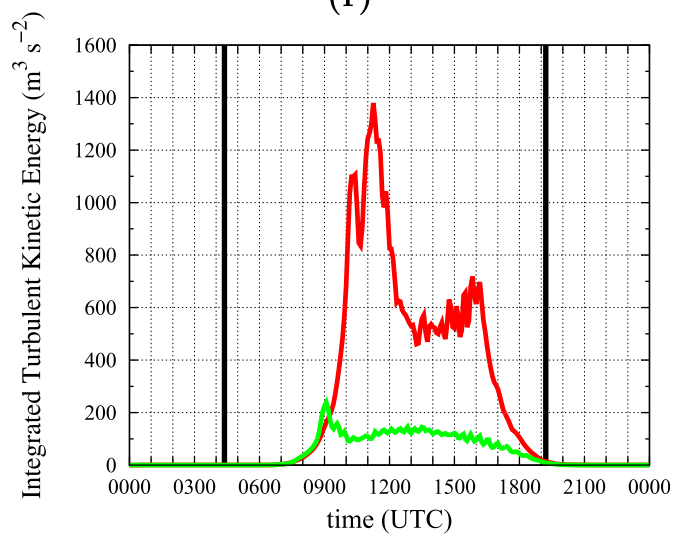

FIG. 2. Modeled (MNH; thick lines) and observed (AWS; lines with filled squares) time series in Campos (red lines) and Ses Salines (green lines) of (a) 10-m wind speed, (b) 10-m wind direction, (c) 1.5-m temperature, and (d) 1.5-m relative humidity. The locations of these surface weather stations are found in Fig. 1a. Also shown are the time series of (e) the TKE at $10 \mathrm{~m}$ AGL and (f) the integrated value in the lowest $1 \mathrm{~km}$ for Campos and Ses Salines. The black vertical lines indicate sunrise and sunset.

the one-dimensional version and using a buoyancy-based mixing length (Bougeault and Lacarrère 1989). It has been validated in several intercomparison exercises, as in Cuxart et al. (2006). The model does not allow the use of alternative turbulence schemes; therefore, the sensitivity of the results to this factor, such as using a first-order scheme, has not been examined. Nevertheless, the above-cited studies show that the current model should 
(a)

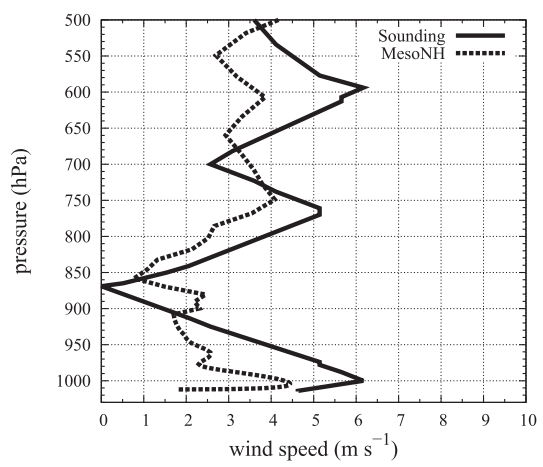

(b)

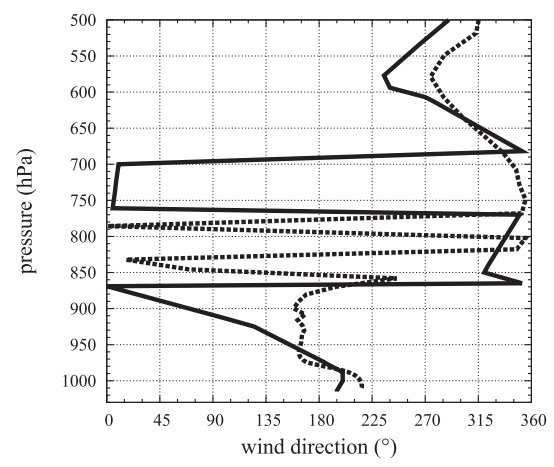

(c)

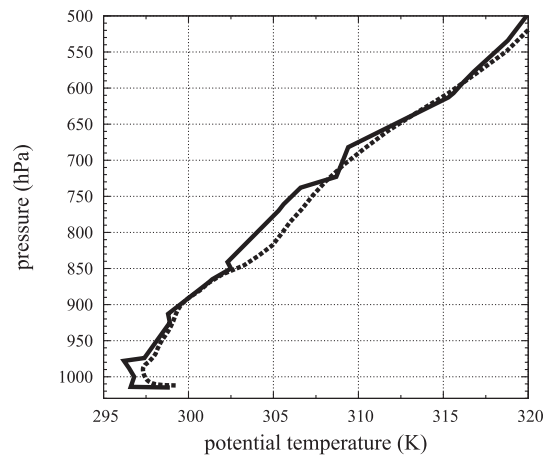

FIG. 3. Vertical profiles observed by the sounding launched near point B in Fig. 1a for 1100 UTC 5 Jun 2010 together with the vertical profiles obtained from the model at the nearest grid point for (a) wind speed, (b) wind direction, and (c) potential temperature.

be able to correctly reproduce the main features of the SB circulation.

It must be stressed that, at this horizontal resolution, the turbulent eddies of a horizontal scale smaller than $2 \mathrm{~km}$ (as for this case) are not resolved, and it is justified to use the turbulence scheme in one-dimensional mode (see, e.g., Bryan et al. 2003; Honnert et al. 2011). The large aspect ratio used between the horizontal and vertical resolution allows one to provide very detailed vertical profiles in the surface layer. It implies the use of very small time steps $(<1 \mathrm{~s})$ to avoid instabilities over slopes as a result of the vertical advection term, however, making the simulation expensive computationally.

The simulation starts at 1200 UTC 4 June 2010, using the European Centre for Medium-Range Weather Forecasts (ECMWF) fields as initial and boundary conditions, and lasts until 0000 UTC 6 June 2010. This allows one to represent the LB of the previous night and to simulate the flow until the decay of the SB. Two domains are used, an outer one with a horizontal resolution of $5 \mathrm{~km}$ that covers the whole Balearic Archipelago and an inner one at 1-km resolution over the island of Mallorca and its immediate sea surroundings. The vertical resolution is extremely fine in the first few hundred meters (typically $5 \mathrm{~m}$ ) to reproduce with detail the lowlevel flow structures. There are 85 vertical levels, and the model top is at $9600 \mathrm{~m}$, with an absorbing layer at the top, where the model prognostic variables are relaxed toward the large-scale values.

\section{c. The budget equations}

The momentum, temperature, and TKE (or $e$ ) budgets are provided by the Méso-NH model, which stores the changes in each variable after exiting the corresponding routine, providing a complete budget that can be inspected for physical interpretation. The temporal

and spatial extent can be chosen by the user. Here, 1-h averages for some selected grid columns are used. The three budgets that will be discussed are (using Einstein's summation convention) written in a form that is suitable for our analysis:

TABLE 1. Summary of the setup of the run made with the Méso-NH model (Lafore et al. 1998).

\section{Domains \\ Inner domain \\ Outer domain \\ Horizontal resolution: inner \\ Vertical resolution \\ (terrain-influenced coordinates) \\ Topography}

Horizontal resolution: outer

Equation system

Lateral boundary conditions

Radiation scheme

Longwave

Shortwave

Advection scheme

Turbulence scheme: TKE scheme

Turbulence scheme: Mixing length

Surface scheme: Soil and vegetation

Surface scheme: Sea and inland waters

Surface scheme: Urban and artificial areas

Surface scheme: Land use

\author{
2 , one-way nested \\ $96 \times 64$ grid points \\ $100 \times 125$ grid points \\ $5 \mathrm{~km} \times 5 \mathrm{~km}$ \\ $1 \mathrm{~km} \times 1 \mathrm{~km}$ \\ Near the ground: $\Delta z=3 \mathrm{~m}$; \\ at $z=500 \mathrm{~m}: \Delta z=7 \mathrm{~m}$; \\ top of the domain: $\Delta z=600 \mathrm{~m}$ \\ 90-m resolution, adapted from \\ Reuter et al. (2007) \\ Durran (1989) \\ Analysis from the ECMWF \\ every $6 \mathrm{~h}$ \\ Morcrette (1990) \\ Mlawer et al. (1997) \\ Fouquart and Bonnel (1980) \\ Flux-corrected second-order \\ centered \\ Cuxart et al. (2000)
}

Bougeault and Lacarrère (1989)

Interactions between Soil, Biosphere, and Atmosphere (ISBA; Noilhan and Planton 1989)

Belamari (2005)

Masson (2000)

"Ecoclimap" (Masson et al. 2003) 
$\frac{\partial U_{i}}{\partial t}=-U_{j} \frac{\partial U_{i}}{\partial x_{j}}-\frac{1}{\rho} \frac{\partial p}{\partial x_{j}}+\delta_{i 3} g \frac{\Delta \Theta_{v}}{\Theta_{v \mathrm{ref}}}+$ Cor $-\frac{\partial \overline{U_{j}^{\prime} U_{i}^{\prime}}}{\partial x_{j}}+$ Dif

$$
\begin{gathered}
\frac{\partial T}{\partial t}=-U_{j} \frac{\partial T}{\partial x_{j}}-\frac{1}{\rho} \frac{\partial R_{j}}{\partial x_{j}}-\frac{\partial \overline{U_{j}^{\prime} T^{\prime}}}{\partial x_{j}}+\mathrm{PC}-\text { Diss, and } \\
\frac{\partial e}{\partial t}=-U_{j} \frac{\partial e}{\partial x_{j}}-\overline{U_{i}^{\prime} U_{j}^{\prime}} \frac{\partial U_{i}}{\partial x_{j}}+\frac{g}{\Theta_{v \mathrm{ref}}} \overline{w^{\prime} \Theta_{v}^{\prime}}-\frac{\partial \overline{U_{j}^{\prime} e}}{\partial x_{j}}-\epsilon .
\end{gathered}
$$

In the momentum budget, Dif stands for the numerical diffusion terms and Cor stands for the Coriolis term (taking the latitude of $39.5^{\circ} \mathrm{N}$ ). In the temperature budget, $R_{j}$ is the net radiation in the $j$ direction, PC corresponds to the sources and sinks related to phase changes, and Diss corresponds to the molecular dissipation into heat. In the $e$ equation, $\epsilon$ means the dissipation of energy, represented here by the Kolmogorov expression, and the divergence of the pressure-TKE correlations is implicitly included in the turbulence transport term. In this simulation, radiation and turbulence divergences are computed only vertically; therefore, the corresponding terms are only in the $z$ direction. Our simulation does not have cloud condensation activated, in agreement with the chosen cloudless period and implying that $\mathrm{PC}=0$. Therefore neither PC nor Dif and Diss (which are very small) will be shown in the figures.

\section{d. The organization of the flow}

Verification of the model against observations is provided in Figs. 2 and 3. The time series at the selected points indicate very good agreement with data, except for a small delay in the arrival of the SB at Campos. The model shows similar values for the TKE in the surface layer near the coast and inland, but the vertically integrated value indicates much deeper turbulence inland. The comparison with the Palma sounding at 1100 UTC (Fig. 3) shows that the model is able to reproduce the vertical structure of the SB (wind direction and temperature), although the modeled wind maximum at lower levels is weaker.

The main SB patterns obtained from the model outputs are shown in Fig. 4, where they are also compared with some results of RR95 and JJ46. The horizontal distribution of the modeled wind at lower levels at local noon (Fig. 4a) indicates mature SB flow from all sides of the island, almost identical to the description of JJ46 (Fig. 4c). Note that the SB at the northwestern side of the island, which is occupied by the very steep and tall Tramuntana range (topping at $1450 \mathrm{~m}$ MSL), cannot progress inland. The other areas, including the three main basins (Palma in the southwest, Campos in the southeast, and Alcúdia in the northeast) and the eastern coast, allow the entrance of marine air to the center of the island, helped by the effect of the upslope flows, as RR95 showed.

The Palma basin has a flat half-circular configuration surrounded by slopes that allows the SB to open and diverge as it progresses inland, whereas the narrower topography of the Campos basin forces the onshore flow to converge and favors a deeper penetration inland. Despite large similarities with the SB distributions in RR95, in our real case, two small and shallow cyclonic vortices above the center and the west of the island do not form. It is worth mentioning that the wind direction is very steady once the SB is set, showing no evidence of wind turning due to the Coriolis effect, probably because the significant topographic upslope forcing determines the direction of the inland flow.

A comparison of Figs. $4 \mathrm{~b}$ and $4 \mathrm{~d}$ allows one to see that, over the basins of Palma and Alcúdia, the vertical structures of RR95 and this study are practically identical, except for the northerly wind aloft that tops the SB system in the present case. Inland penetration in both basins in the lower $500 \mathrm{~m}$, convergence over the center of the island, and divergence aloft (between 1 and $2 \mathrm{~km} \mathrm{MSL}$ ) are the main characteristics. Estimated SB dimensions in the model are in the range of SB characteristics at other locations (e.g., Crosman and Horel 2010). This is in contrast with the asymmetry in the Campos basin, where the topography allows the inland flow from the south to progress farther than the one from the north and with no indication of return flows (Fig. 4e). There are three locations of upward motions (Fig. 4f): one in the southern slopes and two others in convergence areas with the eastern and northern flows.

\section{e. The $S B$ in the Campos basin}

At night, near the coast (Ses Salines, Fig. 2) the wind is practically calm, whereas there is an easterly wind inland (Campos) of $\sim 1 \mathrm{~m} \mathrm{~s}^{-1}$, which is probably a downslope flow from the nearby range, as shown in Cuxart et al. (2007). The model tends to overestimate slightly the wind speed, although the direction is captured well. In the daytime, the observations and the model indicate that the winds are the strongest close to the coastline, with a well-defined direction normal to the coastline. The penetration of the SB front inland to Campos takes slightly more than $1 \mathrm{~h}$, with a small delay in the model. The extra turbulence mixing in the nighttime may explain partially why the model is not able to generate low enough temperatures [as in Jiménez et al. (2008)]. The daytime evolution matches very well the observations in both locations for temperature and humidity, however.

The model temporal evolution of the TKE at $10 \mathrm{~m}$ (Fig. 2e) is a good indicator of the temporal extent and 


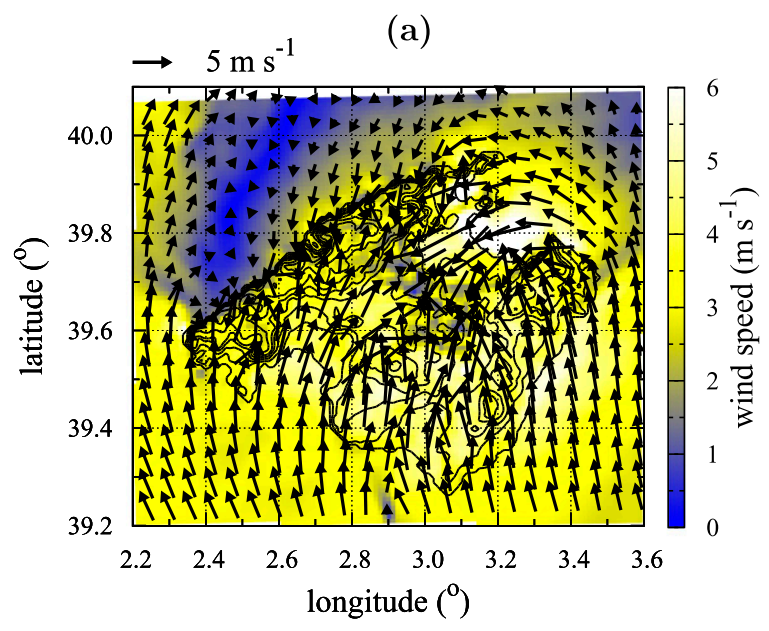

(c)

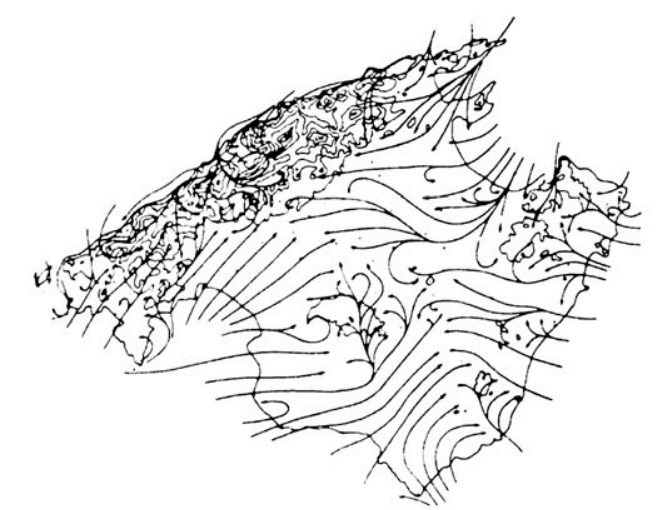

(e)

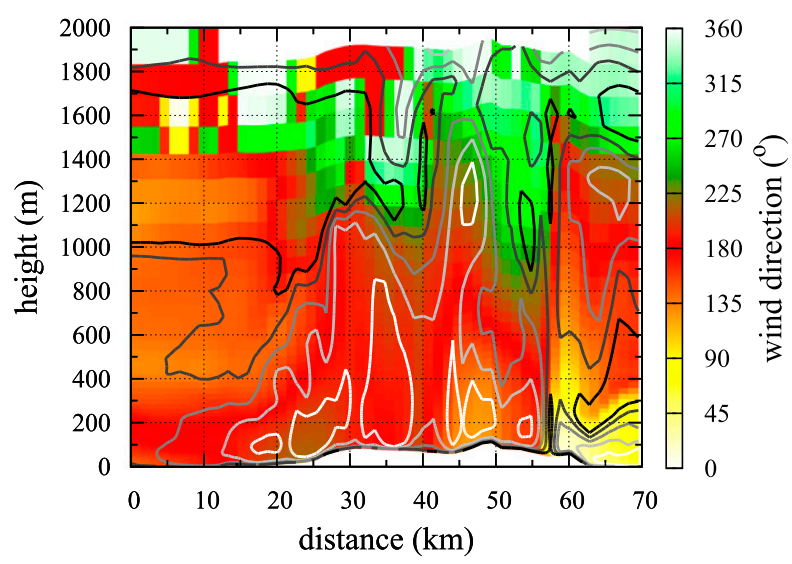

(b)

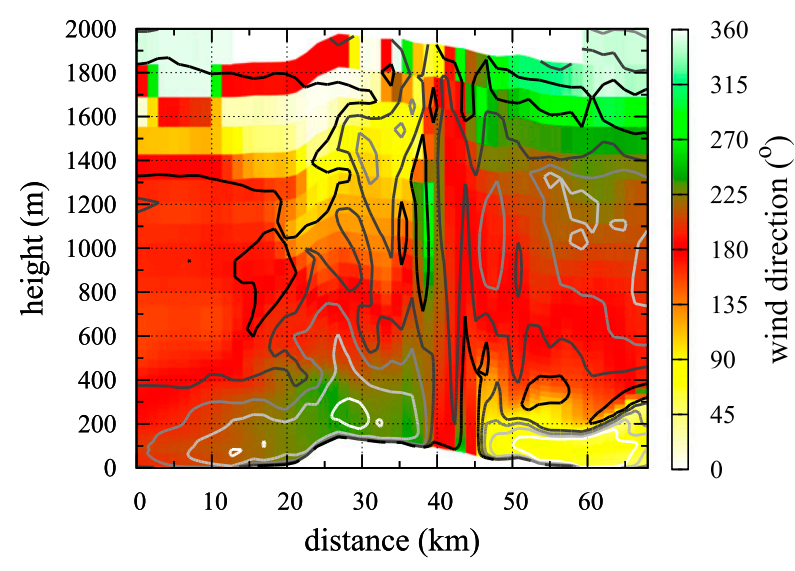

(d)

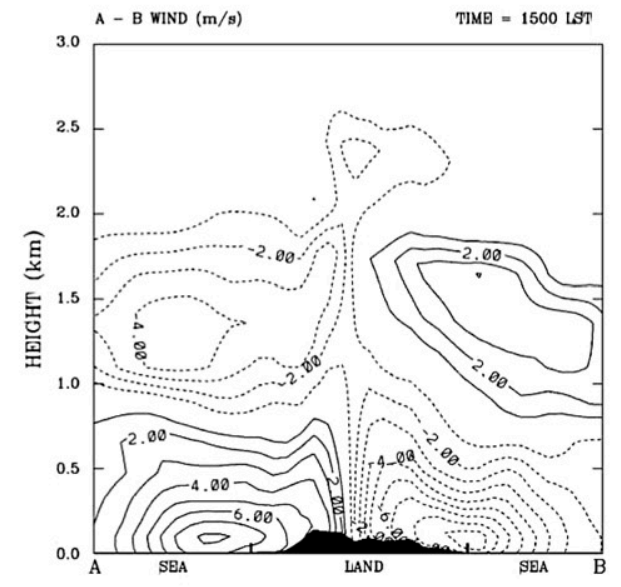

(f)

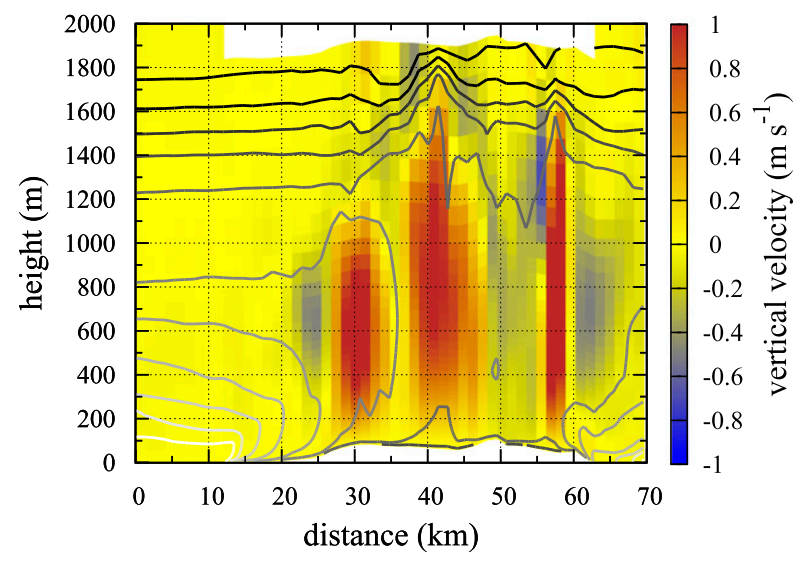

FIG. 4. (a) Horizontal cross section of the 10-m wind vectors together with the wind speed and the topography (black lines) from the model at $1200 \mathrm{UTC}$; (b) vertical cross section of the wind direction (color scale) and the wind speed [lines every $1 \mathrm{~m} \mathrm{~s}^{-1}$, from 2 (black) to 6 (white) $\mathrm{m} \mathrm{s}^{-1}$ ] over the Palma and Alcúdia basins (following the black continuous line in Fig. 1a) at 1200 UTC; (c) near-surface wind, as determined experimentally by JJ46; and (d) vertical cross section (similar to the black thick line in Fig. 1a) of the wind speed over the center of the island for the idealized case (no synoptic wind) of RR95. (e) As in (b), but for a line over the Campos and Alcúdia basins (dashed line in Fig. 1a). (f) As in (e), but for the vertical velocity (color scale) and the potential temperature [lines every $1 \mathrm{~K}$, from 294 (white) to 304 (black) K]. 
(a)

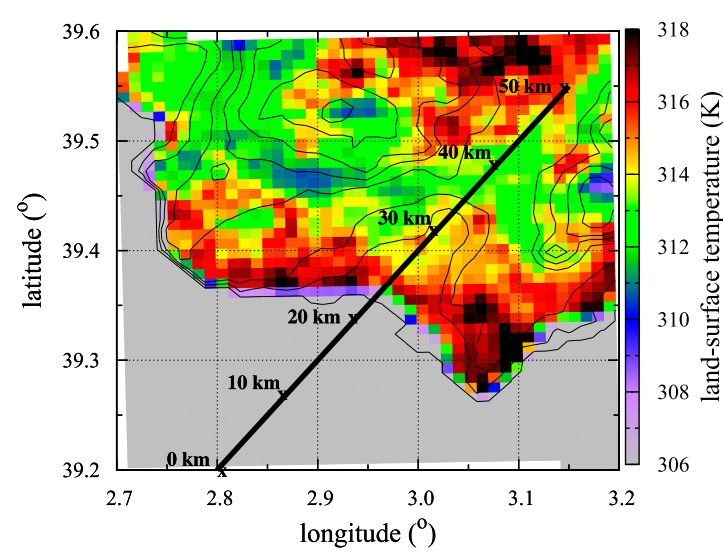

(c)

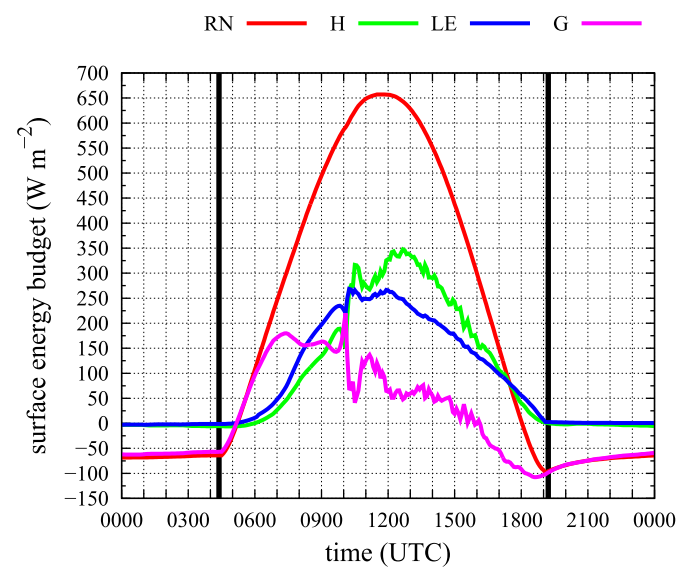

(b)

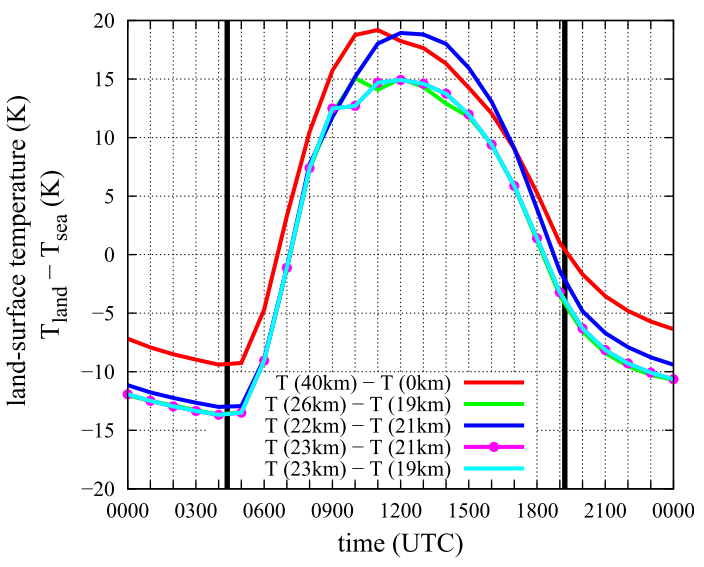

(d)

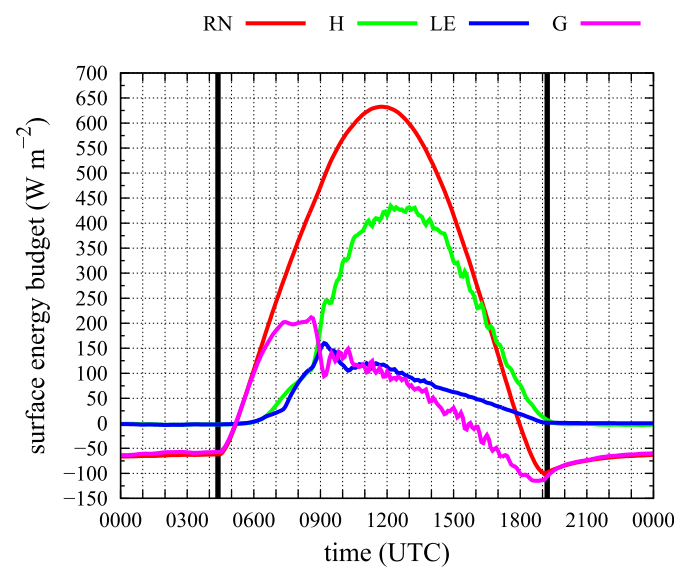

FIG. 5. (a) LST obtained from the model at 1200 UTC 5 Jun 2010. (b) Time series of the difference between LST and SST for several pairs of points along the Campos basin [see these distances in the line in (a)]. Modeled surface energy budgets at (c) Campos and (d) Ses Salines (see locations in Fig. 1a): RN is the net radiation, $H$ is the turbulent sensible heat flux, LE is the turbulent latent heat flux, and $G$ is the ground flux. The black vertical lines indicate sunrise and sunset.

intensity of the SB, showing more turbulence inland than at the coastline during the mature phase at the central part of the day, especially if it is integrated vertically (Fig. 2f). This integrated value has a strong peak when the SB arrives at Campos. Turbulence intensity is unfortunately not recorded at AEMET stations.

The distribution of the land surface temperature as seen by the model at 1200 UTC is shown in Fig. 5a. Of interest is that the coastal area of the Campos basin is warmer than farther inland is, probably because this area is less vegetated and has dryer soils relative to the rest of the island. The temperature difference across the coast reaches $19^{\circ} \mathrm{C}$ in $1 \mathrm{~km}$ (Fig. 5b), about the same difference as between the center of the island and locations that are a few kilometers offshore.

The surface energy budgets for Campos and Ses Salines (Figs. 5c and 5d) indicate that both near the coast and inland, before the SB starts, the solar heating is essentially compensated by the ground heat flux, increasing the surface temperature while there are much smaller sensible heat flux $H$ and latent heat flux. Once the SB is set, the enhanced wind generates larger turbulent heat fluxes and the consequent diminution of the ground flux. Note that the latent heat flux is smaller near the coast than inland (probably because of an imposed climatological low value of the soil moisture there) and $H$ is larger. At 1800 UTC, the net radiation becomes negative at both places, and then the wind speed falls to very low values even if the turbulent heat fluxes are still positive during the following hour.

The inhomogeneous spatial distribution of $H$ here is different from the idealized cases in which $H$ is considered to be idealized (i.e., constant or periodic), such as in LES (Antonelli and Rotunno 2007; Crosman and Horel 
2012), where the one-way $(H-\mathrm{SB})$ interaction dominates. Because $H$ is considered to be the key factor that generates SB (e.g., Crosman and Horel 2010), often a positive feedback relationship between $H$ and SB speed is used (e.g., Bastin et al. 2005; Kala et al. 2010) that can also be qualitatively compared here. Wind speed and $H$ are larger at the coast (Ses Salines) than inland (Campos), but the sum of the turbulent sensible and latent heat fluxes is larger inland, which is consistent with higher TKE values at this point. The higher $H$ and lower latent heat fluxes at Ses Salines are due to the drier soil there relative to farther inland and make it not possible to do a direct comparison with the ideal cases just mentioned. The inland flow is shallower over the coast than inland, however, and the accompanying advection of colder marine air creates vertical temperature gradients that affect $H$ values (in two-way $H$-SB interaction). It is obvious that a real inhomogeneous surface with different soil moisture contents can have a significant impact on the SB characteristics (Kala et al. 2010) and also a very complex influence on the realistic distribution of $H-\mathrm{SB}$ speed relations.

\section{Budgets for the Campos basin}

Because the model compares well to the historic references and to the available observations, it is legitimate to inspect the model budgets to see which processes have the most important role, at what time, and in which layers. Focus will be on what are the main processes that drive each stage of the phenomenon. Since the budgets in the model make it possible to study also what is happening over the sea, where observations are rare, they can provide a more complete vision of the evolution of the SB.

\section{a. Temperature}

As mentioned in the previous section, there is a very large and sustained temperature gradient across the coastline, even when the SB is fully developed, maintaining different $\mathrm{ABL}$ regimes at both sides. Over the land, a shallow convective ABL develops as the cold air travels over the heated surface until the air is evacuated upward over the inland slopes. Over the sea, there is a weakly stably stratified $\mathrm{ABL}$, with turbulence production only by shear once the SB is established. The ABL becomes less stable as the SB approaches the coast and blows over slightly warmer waters in the internal boundary layer. Even when the SB is at its maximum development, this two-system structure stays in place, with a well-defined limit over the coast, independent of the SB front, which advances inland in the morning hours. Therefore, from here onward, the analyses of budgets show the results above both surfaces separately: for land and for sea.
Figure 6 presents some selected plots for the temperature budget [Eq. (2)] at $6.5 \mathrm{~km}$ offshore and $3.5 \mathrm{~km}$ inland (corresponding to positions 15 and $25 \mathrm{~km}$, respectively, along the line in Fig. 5a). The profiles in Figs. $6 \mathrm{a}$ and $6 \mathrm{~b}$ were averaged for $1 \mathrm{~h}$ between 1400 and 1500 UTC (a mature stage). In both points radiative warming dominates the surface layer, and turbulence distributes the warm air in a layer up to $250 \mathrm{~m}$ above the land and $100 \mathrm{~m}$ above the sea. This warming is compensated by cold advection at both locations, produced by the lower branch of the SB. Over the sea point, the cold advection is not compensated at the layer centered at $200 \mathrm{~m}$, and there is a tendency to cool in that layer. Between 400 and $700 \mathrm{~m} \mathrm{AGL}$, there is weak warm advection, which can be linked to the heating by very weak downward flow at those heights.

For the 10-m temperature budget along the line in Fig. 5a (Fig. 6c), air warming caused by radiation and turbulence is compensated only by advection over the land and the sea, and a maximum is observed at the land coastal area, where the maximum temperature gradient takes place, as described in the previous section. Since this is a mature phase of the $\mathrm{SB}$, it is clear that the ventilation is not able to eliminate this temperature difference as the day progresses.

The time evolution is exemplified in Fig. 6d for the land point at $10 \mathrm{~m}$. Sunrise is at $0423 \mathrm{UTC}$; after $0500 \mathrm{UTC}$, radiation and turbulence start warming the surface. Advection begins at 0800 UTC with the consequent increase of the turbulent warming by mechanical and thermal mixing, which reaches its maximum at 1400 UTC, slightly delayed with respect to the radiation. The advection follows an evolution that is practically symmetrical to that of the turbulence, and both diminish gradually between 1400 and 1900 UTC, when the SB dies out. As the tendency indicates, warming only takes place until 1100 UTC. Afterward, the system is in balance, and the temperature is essentially constant until 1700 UTC.

As a side note, in the nocturnal part there is warm advection, probably because of the adiabatic warming by compression of the down-valley flow. This air, once over the sea, is colder than the surface, however, and generates a shallow convective boundary layer (not shown) that may have a dynamic role in the morning hours.

\section{b. Turbulence}

Acting in a similar way to the turbulence budget [Eq. (3)], we see in Figs. 7a and $7 b$ how the profiles averaged between 1400 and 1500 UTC indicate a very different behavior over the sea and the land. For the latter, the magnitude of the terms is much larger than over the sea, as is the vertical extension, which is in agreement with the vertically integrated TKE shown in Fig. 2f. The turbulence 
(a)

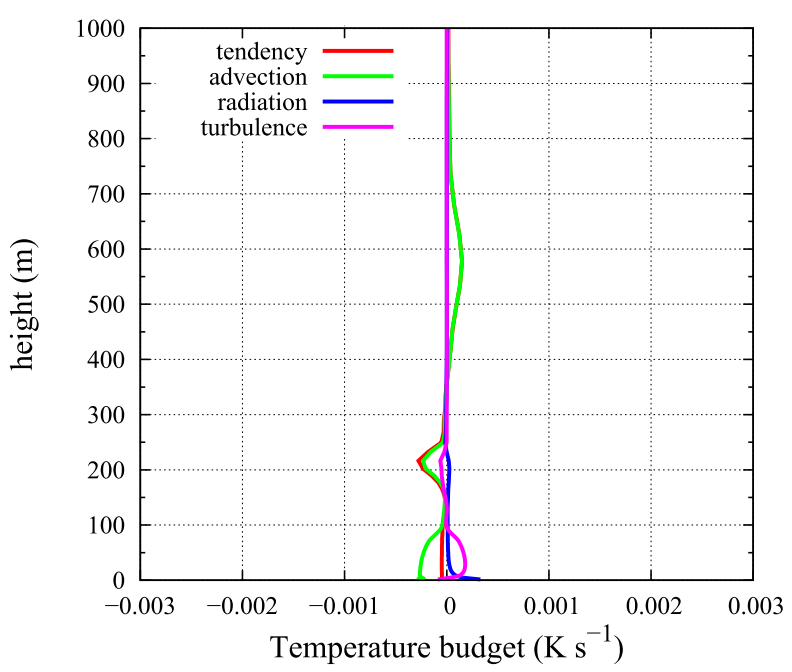

(c)

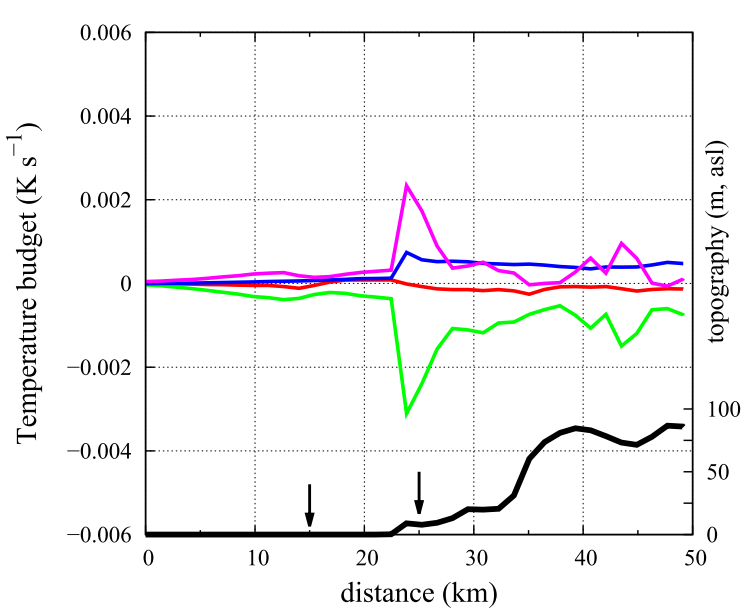

(b)

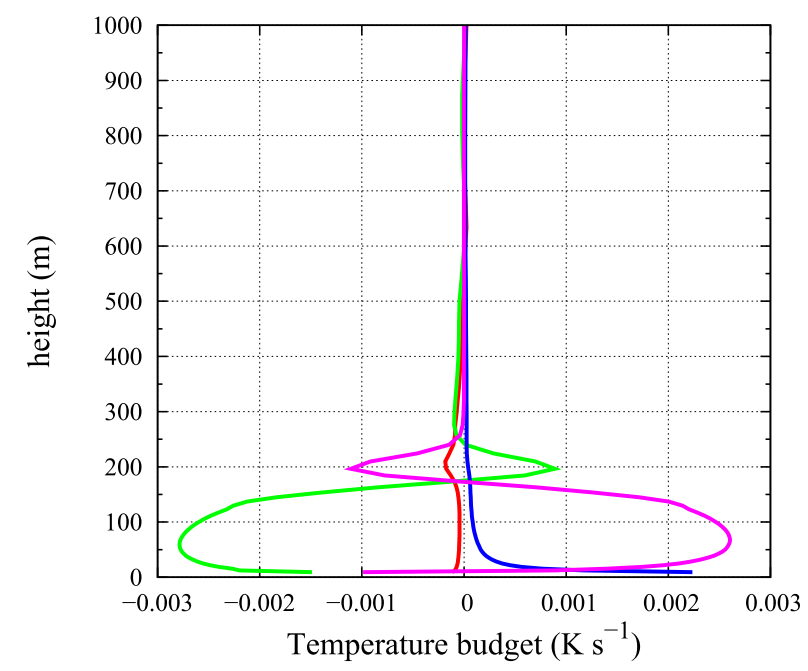

(d)

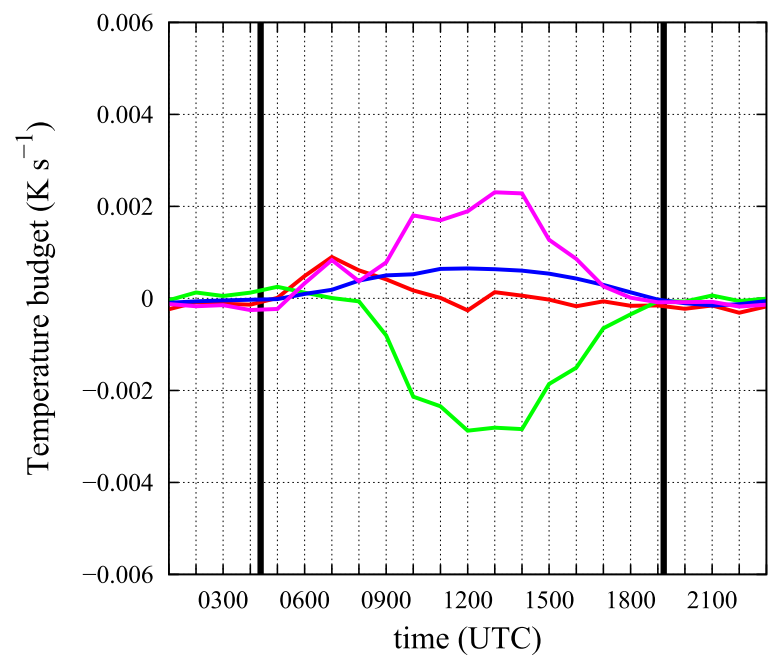

FIG. 6. Temperature budgets [Eq. (2)]. Hourly (1400-1500 UTC) averaged profiles for points (a) $6.5 \mathrm{~km}$ offshore and (b) $3.5 \mathrm{~km}$ inland [positions indicated in (c) and Fig. 5a]. (c) The 10-m-AGL budgets following a line normal to the coastline (line in Fig. 5a); the black line represents the underlying terrain, and arrows show the positions of the profiles shown in (a) and (b). (d) Time series of the budget at $10 \mathrm{~m}$ AGL for a point $3 \mathrm{~km}$ inland [position $25 \mathrm{~km}$ in (c)], with sunrise and sunset indicated by black vertical lines.

in the surface layer is essentially due to shear production, which is supplemented over the land by convection up to above $200 \mathrm{~m}$ AGL, whereas over the sea turbulence is weak and is restricted to the lowest $50 \mathrm{~m}$ MSL.

Figure $7 \mathrm{c}$ illustrates how the different terms in the TKE budget in the surface layer behave as a function of the distance to the coastline in the mature phase of the SB. It is noteworthy that the shear production term is the largest over the land in this layer, with systematically larger values over the slopes. Instead, the thermal production has an almost constant value of approximately one-half of the shear production.
The time series for the inland point at $10 \mathrm{~m}$ AGL (Fig. 7d) shows that the turbulence of thermal origin starts shortly before $0700 \mathrm{UTC}$, almost $2 \mathrm{~h}$ after sunrise. This means that almost $2 \mathrm{~h}$ are necessary to erode the previous nocturnal surface inversion and form the SB flow that arrives to the point of interest at 0900 UTC. Until 1100 UTC, thermal production is larger than the shear production. After that, up to 1600 UTC, the shear (particularly along and behind the SB front) is the main factor generating turbulence, whereas in the decaying phase the thermal and shear production are of similar intensity. 
(a)

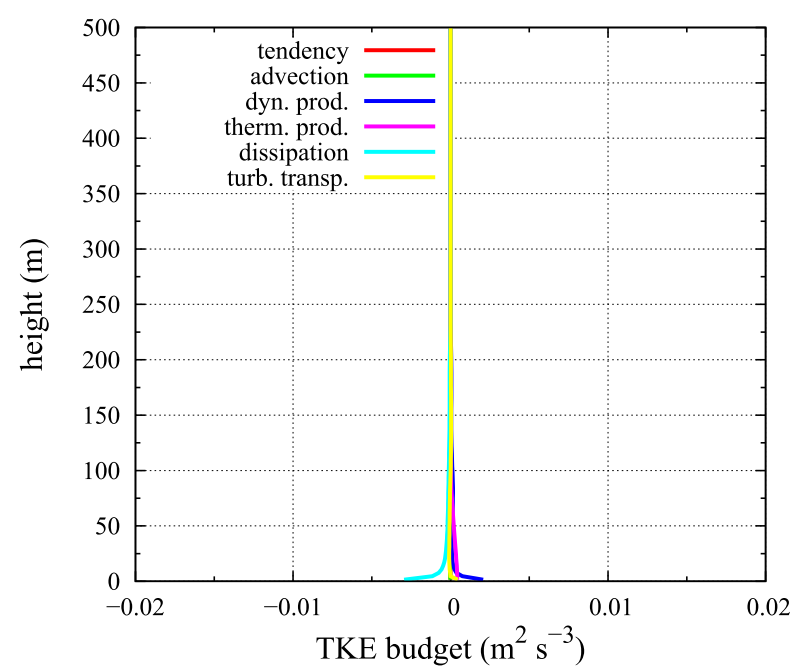

(c)

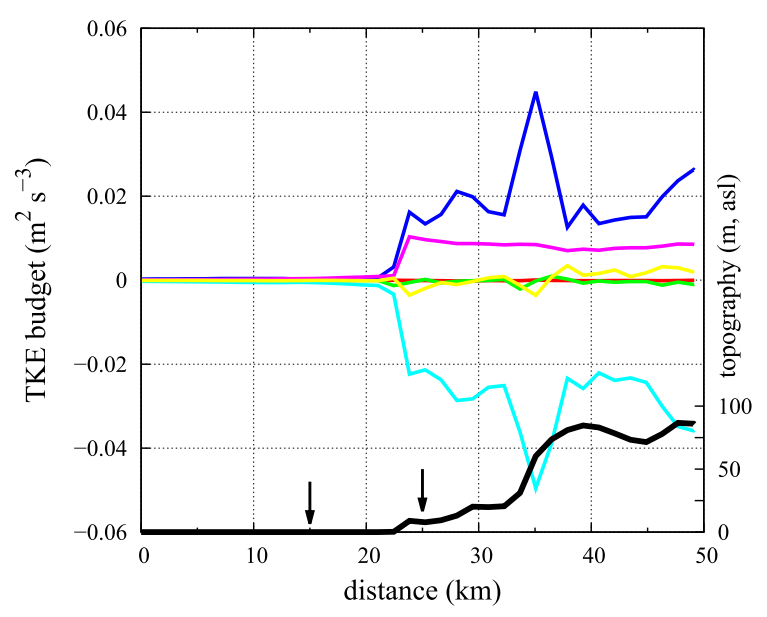

(b)

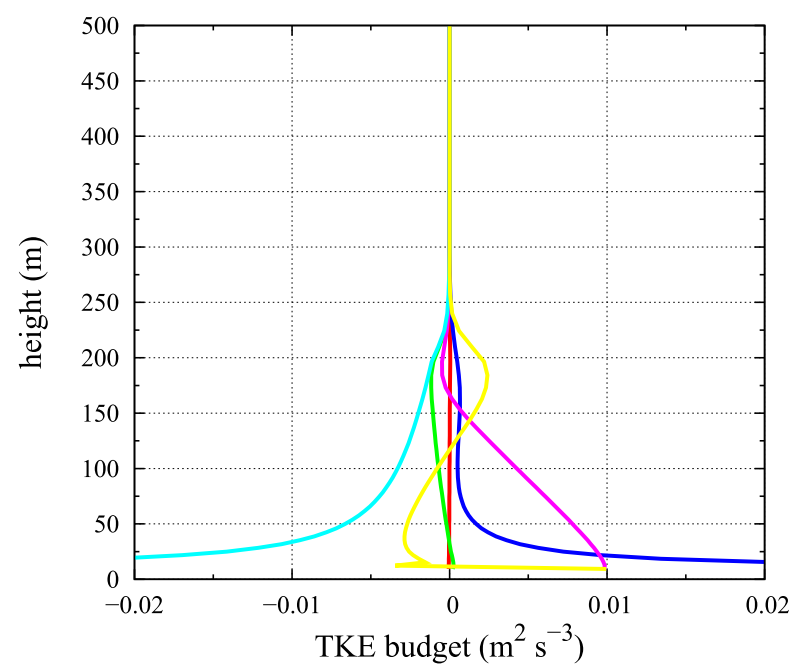

(d)

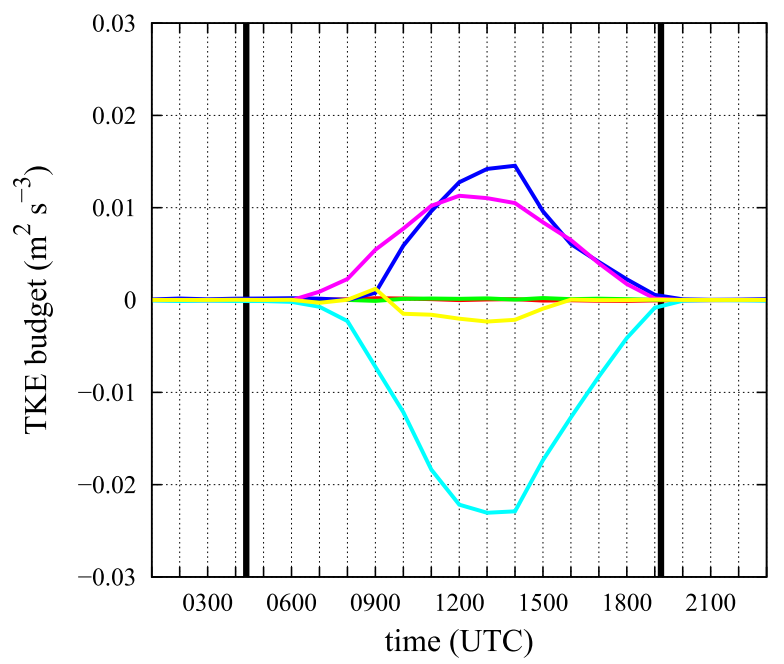

FIG. 7. As in Fig. 6, but for the TKE budget [Eq. (3)].

\section{c. Momentum}

The model provides budgets [Eq. (1)] for the three velocity components, where $V$ is south-north, $U$ is westeast, and $W$ is the vertical component. The SB starts blowing normal to the coastline (southwest-northeast direction) and veers to south-north at about 1000 UTC. Therefore, we will focus on the budget of the $V$ component as a good approximation to the horizontal wind.

Figure 8 shows, for one point over the sea and one inland, the hourly averaged profiles of the budgets at 0830 UTC (just when the SB starts), at 1030 UTC (in its development phase), and at 1430 UTC (in the mature phase). In the early morning (Figs. 8a,b) over the sea, the only significant term in the budget is the pressure gradient (PG) term below $200 \mathrm{~m}$, uncompensated and giving rise to an acceleration, which is relatively consistent with the "sideways" theory (e.g., Miller et al. 2003). Over the land, the pressure term is partially compensated below $100 \mathrm{~m}$ by the turbulence mixing. Note that the net contribution of the three advection terms over land is positive below $100 \mathrm{~m}$ (acceleration inland), as is the PG term for the first $200 \mathrm{~m}$ AGL.

In the development phase (Figs. 8c,d), the PG term is the main forcing up to $400 \mathrm{~m}$ above both the sea and the land, and it becomes very small but negative between 400 and $1000 \mathrm{~m}$, which implies acceleration at this layer toward the sea due to it. Compensation is provided by 
(a)

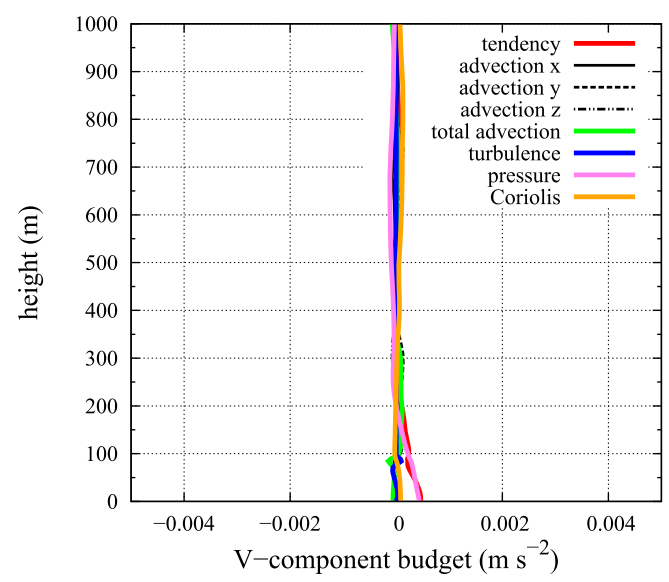

(c)

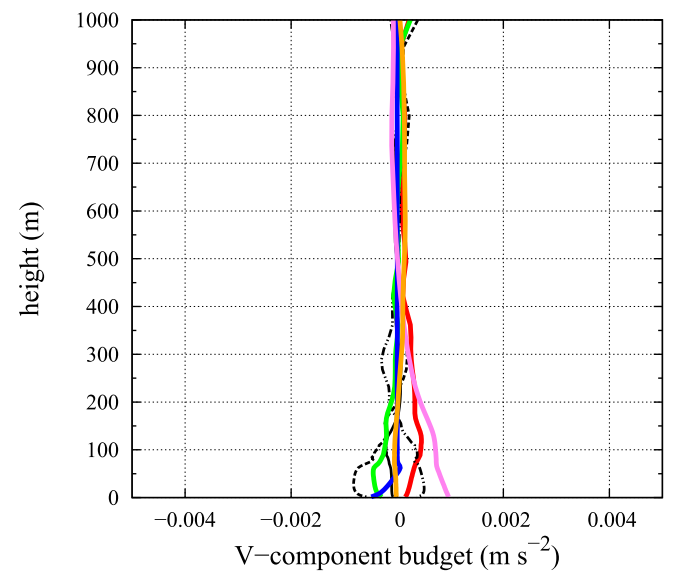

(e)

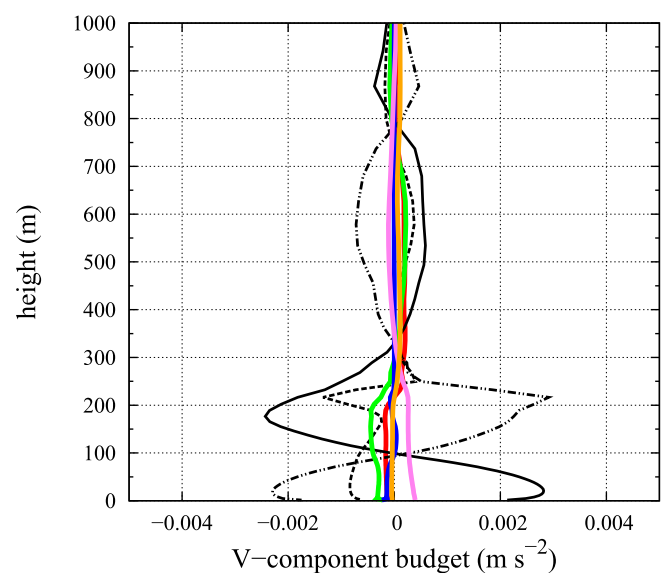

(b)

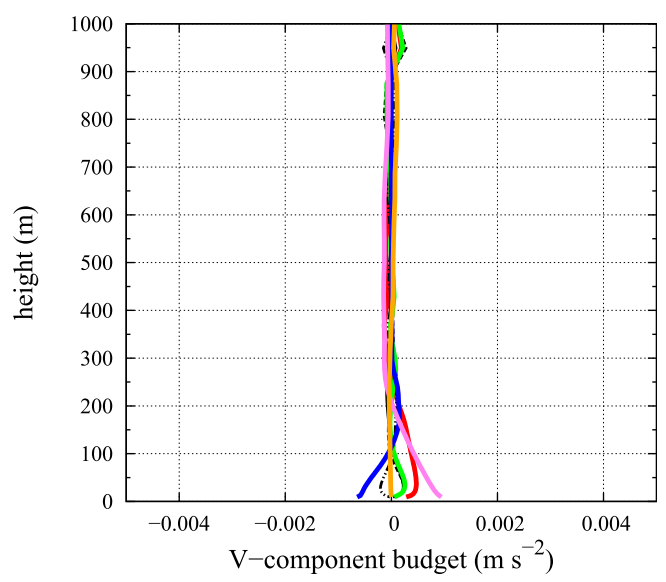

(d)

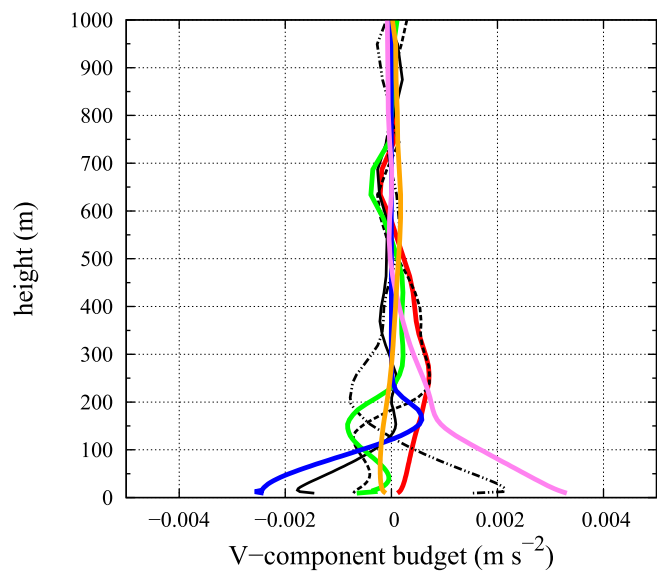

(f)

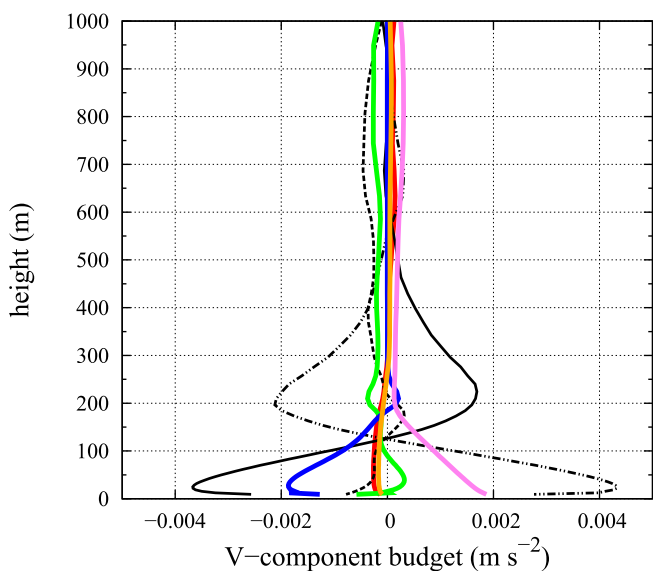

FIG. 8. The 1-h-averaged profiles of the $V$-component budget [Eq. (1)] for points 15 and $25 \mathrm{~km}$ in Fig. 5a (corresponding to points $6.5 \mathrm{~km}$ offshore and $3.5 \mathrm{~km}$ inland, respectively) at different instants: during 0800-0900 UTC for points (a) 15 and (b) $25 \mathrm{~km}$; (c),(d) as in (a) and (b), but during 1000-1100 UTC; (e),(f) As in (a) and (b), but during 1400-1500 UTC. 
(a)

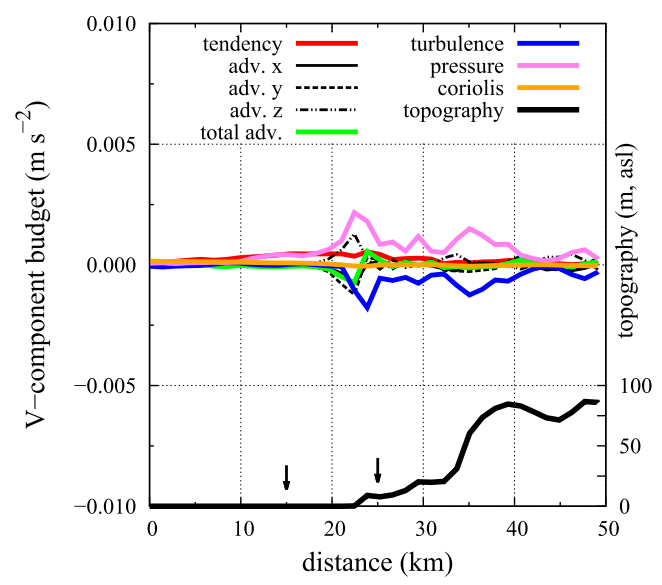

(c)

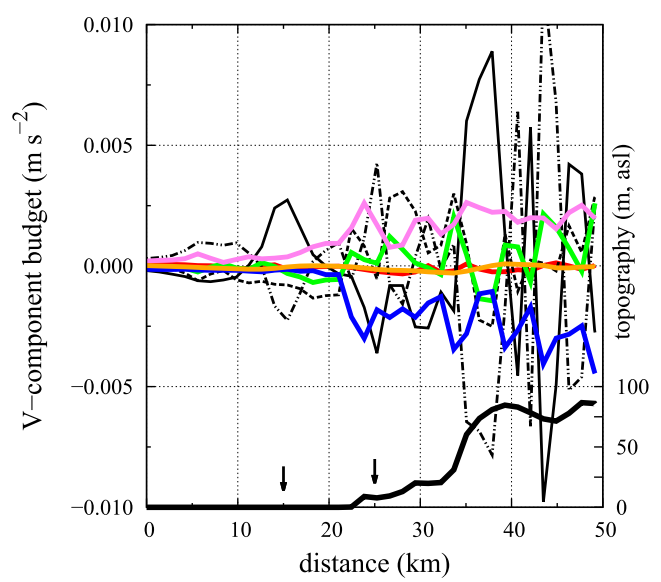

(b)

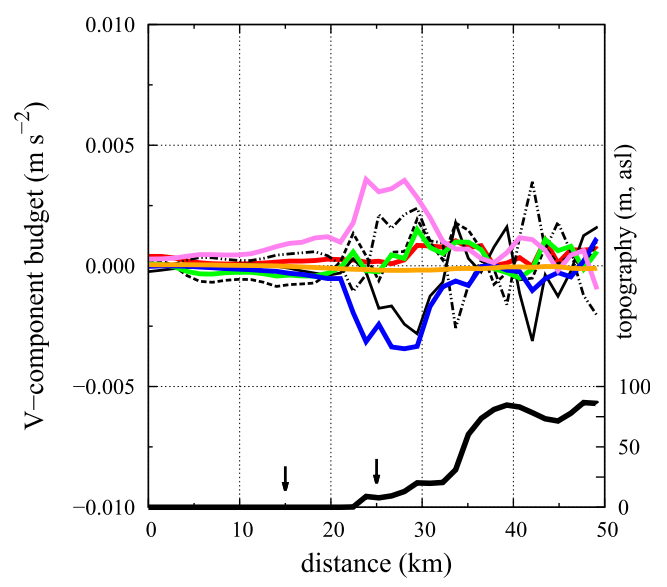

(d)

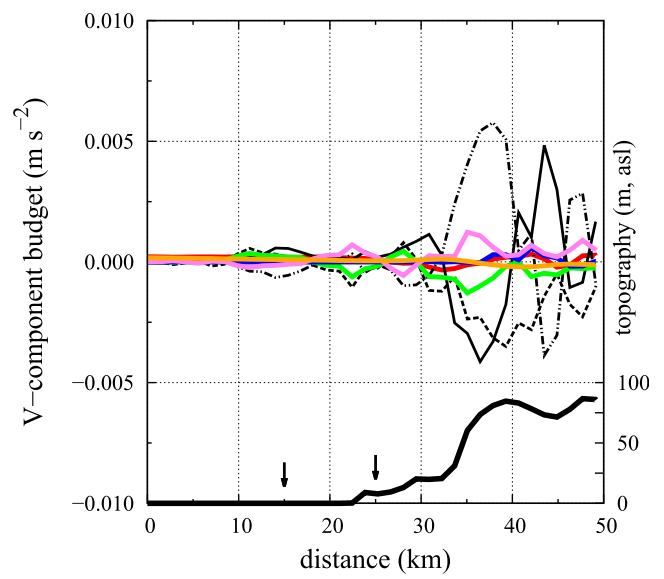

FIG. 9. The $V$-component budget [Eq. (1)] at $10 \mathrm{~m}$ AGL averaged over $1 \mathrm{~h}$ along a line normal to the coast (the line in Fig. 5) at different instants: (a) 0800-0900 UTC, (b) 1000-1100 UTC, and (c) 1400-1500 UTC. (d) As in (c), but at $500 \mathrm{~m}$ AGL.

turbulence in the lowest $200 \mathrm{~m}$ over the land and $70 \mathrm{~m}$ over the sea and by advective motions. The advection by the three components and the total advection of the $V$ component are plotted. At this time, the $y$ advection of $V$ is negative in the lower branch, and, since $V$ is positive, this is consistent with the inland acceleration of the flow. The vertical advection of $V$ has the opposite sign, however, and this implies, taking $W$ to be positive, a decrease of $V$ with height.

The sum of these large single advection terms finally provides a small net advection effect, in this case opposing the PG below $200 \mathrm{~m}$, but adding above. It is noteworthy to see that this net effect is reached through very important motions in the three dimensions of space. The relevance of the advection terms is even more stressed in the mature phase (Figs. 8e,f), when they are the major terms (especially over the sea), implying intense motions, and, although their combined effect is not preponderant in the lowest $100 \mathrm{~m}$, advection above is the only compensatory term to the PG term.

Figure 9 shows that, in the surface layer, the PG term is positive for every point in the line at the three selected times and is mostly balanced by the turbulence mixing, whereas compensatory motions take place to fulfill the rest of the balance. In the morning, these are mostly restricted around the coastline, but they become stronger and much more widely distributed as the time advances. At $500 \mathrm{~m}$ in the mature phase, it can be seen that the PG term is slightly negative above the sea while over the land there are intense motions over the slope. At this layer, the turbulence is essentially irrelevant.

If the time series are inspected for the two points of interest at 10 and $500 \mathrm{~m}$ (Fig. 10), at the surface layer over land, the main terms are the PG and the turbulence, 
(a)

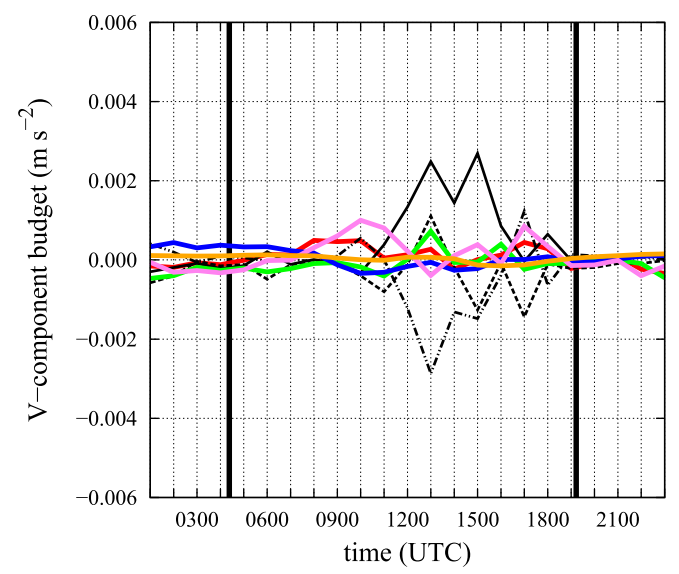

(c)

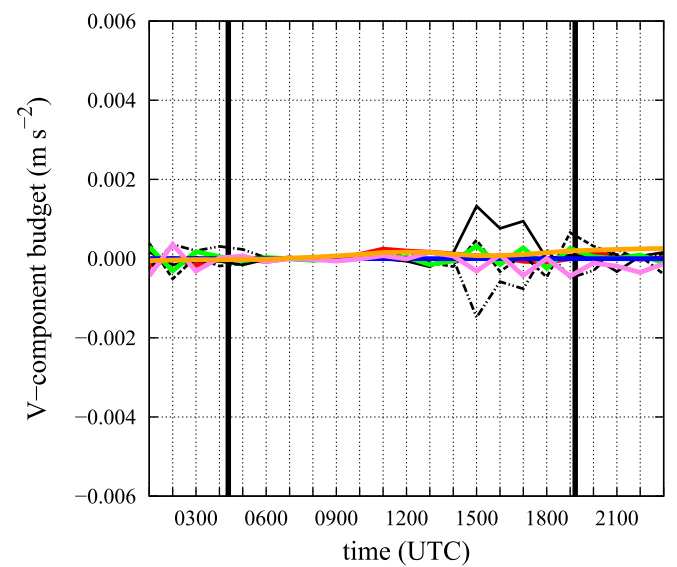

(b)

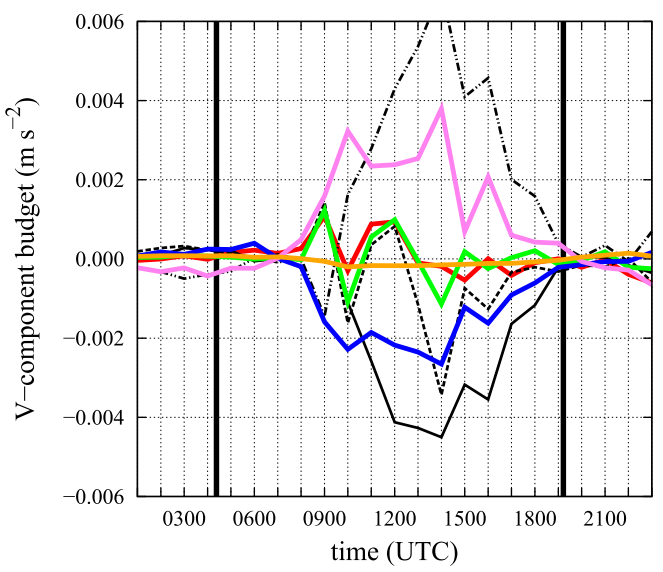

(d)

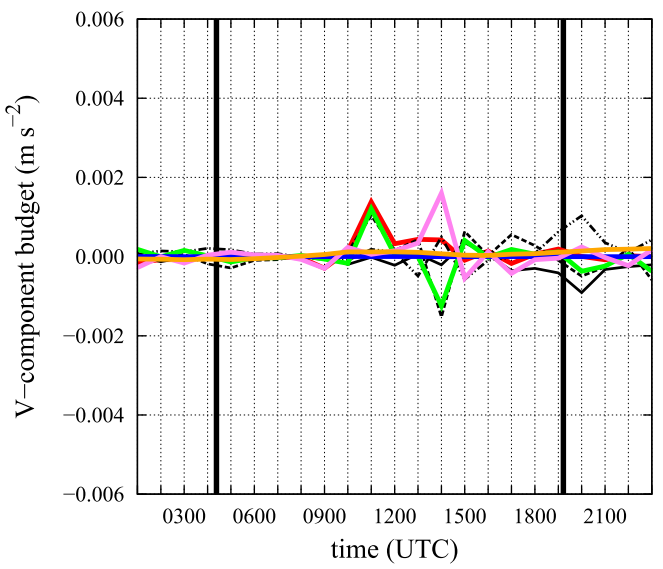

FIG. 10. Time series of the $V$-component budget [Eq. (1)] for points 15 and $25 \mathrm{~km}$ in Fig. 5a (corresponding to points $6.5 \mathrm{~km}$ offshore and $3.5 \mathrm{~km}$ inland, respectively). The key for the lines is found in Fig. 9, and the black vertical lines indicate sunrise and sunset. Budgets are computed at 10-m-AGL height and at points (a) 15 and (b) $25 \mathrm{~km}$. (c),(d) As in (a) and (b), but at $500 \mathrm{~m}$ AGL.

with a significant contribution from advection, especially in the transition periods. Over the sea, advection is often the most important term, except during the first morning hours. At $500 \mathrm{~m}$ MSL, the terms are very weak over the sea in the afternoon, with advective motions present and negative PG, whereas these terms are larger from midmorning over the land, with PG becoming also negative from 1500 UTC.

A comment must be made on the Coriolis term. Contrary to SB flows over the nearby IP, neither the observation nor the simulations display a turning of the wind in the afternoon for our problem basin. Looking at Figs. 8-10, it is seen that the Coriolis contribution is very small. The reason for the lack of turning in the lower layers during the first six hours and for being too small of an effect has been discussed by many (e.g., Crosman and Horel 2010) but the steadiness of the direction in the afternoon may be linked to the local topography (Prtenjak et al. 2008; Sakazaki and Fujiwara 2008); here, the upslope flows in the basin may make their direction prevail and deter the corresponding Coriolis wind turning.

\section{The temporal evolution of SB}

Here, the time evolution of the modeled SB is described in five phases on the basis of the information obtained from the model budgets for this particular case. A summary of the section can be found in Table 2 .

\section{a. Previous and preparatory phases}

In the final part of the night, the cold air flowing off the island has created a shallow, weakly unstable ABL over the sea while there is a stably stratified ABL over the land. Farther offshore the stratification is stable. The 
TABLE 2. Main features of the different phases of the studied sea-breeze case. Here $T$ indicates temperature.

\begin{tabular}{|c|c|c|c|c|c|}
\hline \multirow[b]{2}{*}{ Phase } & \multirow{2}{*}{$\begin{array}{l}\text { Interval } \\
\text { (UTC) }\end{array}$} & \multirow[b]{2}{*}{ Patterns } & \multicolumn{3}{|c|}{ Budgets and processes in surface layer over land } \\
\hline & & & $T$ & TKE & $V$ \\
\hline Previous & $0430-0730$ & $\begin{array}{l}\text { Cold offshore wind; } \\
\text { initial warming } \\
\text { of land; } \\
\text { LST }<\text { SST }\end{array}$ & $\begin{array}{l}\text { Warming over land } \\
\text { uncompensated }\end{array}$ & Thermal production & $\begin{array}{l}\text { Negative pressure } \\
\quad \text { gradient (toward sea) }\end{array}$ \\
\hline Preparatory & $0730-0900$ & $\begin{array}{l}\text { Offshore wind stops; } \\
\text { LST > SST; CBL } \\
\text { building over land; } \\
\text { wind inland just over } \\
\text { the coastline }\end{array}$ & $\begin{array}{l}\text { Initial inland cooling } \\
\text { close to the coast }\end{array}$ & Thermal production & $\begin{array}{l}\text { Pressure gradient } \\
\text { changes sign }\end{array}$ \\
\hline Development & 0900-1200 & $\begin{array}{l}\text { Wind inland; front } \\
\text { speed } \approx 3 \mathrm{~m} \mathrm{~s}^{-1} ; \max \\
\text { turbulence; } \\
\text { LST } \gg \mathrm{SST}\end{array}$ & $\begin{array}{l}\text { Cooling by marine } \\
\text { advection equilibrates } \\
\text { radiation/turbulence } \\
\text { warming }\end{array}$ & $\begin{array}{l}\text { Shear production starts } \\
\text { and becomes larger } \\
\text { than thermal } \\
\text { production at the end }\end{array}$ & $\begin{array}{l}\text { Acceleration inland; } \\
\text { main terms: } \\
\text { pressure and } \\
\text { turbulence }\end{array}$ \\
\hline Mature & $1200-1500$ & $\begin{array}{l}\text { Wind, TKE, and } \\
\text { LST-SST } \\
\text { constant; } T \text { slowly } \\
\text { decreasing }\end{array}$ & $\begin{array}{l}\text { Marine advection } \\
\text { compensates } \\
\text { turbulence/radiation }\end{array}$ & $\begin{array}{l}\text { Shear production larger } \\
\text { than thermal production }\end{array}$ & $\begin{array}{l}\text { All terms decrease } \\
\text { with time }\end{array}$ \\
\hline Decay & $1500-1900$ & $\begin{array}{l}\text { Wind decreases, turning } \\
\text { near the coast; } T \text { and } \\
\text { TKE decrease; } \\
\text { LST-SST weakens } \\
\text { and changes sign }\end{array}$ & $\begin{array}{l}\text { All terms decay until } \\
\text { nighttime values }\end{array}$ & $\begin{array}{l}\text { Shear and thermal } \\
\text { production terms } \\
\text { similar, decreasing } \\
\text { until they nullify at } \\
\text { sunset }\end{array}$ & $\begin{array}{l}\text { Pressure term } \\
\text { weakens but stays } \\
\text { positive (flow inland); } \\
\text { turbulence not } \\
\text { compensating }\end{array}$ \\
\hline
\end{tabular}

down-valley wind extends to $\sim 100 \mathrm{~m}$ AGL and sustains weak shear-generated turbulence mixing, even over the sea, where it tops the unstable surface layer.

After dawn, when the land is significantly colder than the sea, radiation warms the land surface and erodes the surface thermal inversion, becoming warmer than the sea at about $3 \mathrm{~h}$ after sunrise. This seems to be when the down-valley flow definitely stops, destroyed by convection, with the PG term changing sign both over the land and over the sea (Figs. 10a,b). We could call this the previous phase, since it occurs while the offshore flows are still present but are progressively weakening through the action of solar radiation over the land.

After the disappearance of the surface inversion, the land surface heating continues and, through convective turbulence, leads to the construction of a PG strong enough to overpass the opposing and delaying effect of turbulence over the land (Fig. 10b). We may call this period the preparatory phase. Figure $9 \mathrm{~b}$ indicates that, before the SB starts, there is equilibrium between the growing PG and turbulence terms over the land and that the tendency implies some acceleration for the first few kilometers inland. Figure 8 shows clearly that, at 0830 UTC over the sea, the wind has already started, uncompensated, whereas, over the land, it is delayed by turbulence in the lowest $100 \mathrm{~m}$, but not between 100 and $250 \mathrm{~m}$. In fact, the shear production of turbulence is very small at that time (Fig. 7c), indicating that the SB is still not blowing in the lower layers. There is not any clear signal of pressure forcing in the layers above $200 \mathrm{~m}$ at that time.

\section{b. Development phase}

From approximately 0900 to 1200 UTC, as seen in Fig. 2a, the wind speed increases both near the coast and inland, the direction veers from normal to the coast to south, and the temperature rise stops; we call this part the development phase, characterized by the domination of the thermal production over shear production of turbulence. As the wind speed increases, however, so do the turbulent heat fluxes (Figs. 5c,d), and the thermal and dynamical production become of similar importance after 1100 UTC (Fig. 7d). Whereas the sea points are basically cooled by offshore advection, the land points have strong radiative and turbulent warming compensated by advection such that the temperature does not rise. The SB propagates inland at a speed of $\sim 3 \mathrm{~m} \mathrm{~s}^{-1}$, reaching the terrain slopes about $1.5 \mathrm{~h}$ after the start of the phase.

The momentum budget (Figs. 8c,d and 9b) indicates that the PG term (which reaches its maximum in this phase) represents the only active forcing, in agreement with the dominance of the thermal production of turbulence. It is positive over the land and over the sea up to $400 \mathrm{~m}$. Turbulence opposes it, but significantly only in the layer up to $200 \mathrm{~m}$ over the land. Between 250 and $500 \mathrm{~m}$ AGL, the net advection and the PG term add and produce a positive acceleration inland, which is not 
present in any of the other phases. There is a similar structure of the opposite sign (accelerating offshore) between 600 and $700 \mathrm{~m}$ AGL. Note that through this phase the temperature gradient between the sea and the land stops increasing (Fig. 5b).

\section{c. Mature phase}

At 1200 UTC, near the center of the island, a convergence zone is formed with significant vertical velocities. We consider this to be the beginning of the mature phase. This is earlier than over larger islands (with radii $>$ $45 \mathrm{~km}$ ), peninsulas, or the IP (Azorin Molina et al. 2009), because of limited land area. This was also indicated by studies about the SB over circular islands (e.g., Mahrer and Segal 1985; Jiang 2012).

Between 1200 and 1500 UTC, the wind regime is essentially steady, especially near the coastline (Fig. 2). The wind blows at speeds near $5 \mathrm{~m} \mathrm{~s}^{-1}$ at $10 \mathrm{~m}$, and the temperature and humidity stay nearly constant. This indicates a slowdown of SB inland penetration in the early afternoon that is due to larger afternoon TKE shear production, vertical advection, and a smaller PG inland (Fig. 8). This slowdown has been observed or modeled at other locations (e.g., Miller et al. 2003; Crosman and Horel 2010; Robinson et al. 2013). Figure 6e displays the height of the jet between 50 and $200 \mathrm{~m}$ with speeds above $6 \mathrm{~m} \mathrm{~s}^{-1}$ and a well-defined upward branch as it impinges over the slopes $15 \mathrm{~km}$ inland. Despite the significant wind over the coastline, the LST there has maximum values and the horizontal surface temperature gradient remains very strong (Fig. 5a).

The combined inspection of the temperature and momentum budgets at 1430 UTC over the sea and the land indicates that there are separated behaviors on both sides of the coastline. Below $200 \mathrm{~m}$ AGL, the PG term is compensated by turbulence over the land and by cool advection over the sea. Above that height up to $1000 \mathrm{~m}$, the PG has opposite sign, being negative over the sea and positive over the land. As a consequence, the respective compensating advection terms are also opposite, with advection offshore over the land and inland over the sea, indicating a convergence zone above $200 \mathrm{~m}$ over the coastline and an effective separation between the marine and land boundary layers.

\section{d. Decay phase}

After 1500 UTC, the wind speed decreases systematically until sunset, with steady direction (Fig. 2). This coincides with a decrease of the temperature over the land and a strong diminution of the net radiation and the heat fluxes, lowering significantly the difference between LST and SST (Fig. 5b). The turbulence stays qualitatively the same as before but loses its strength (Fig. 7d).
The PG term (Fig. 10) over the land weakens as time advances, as do the advective motions. Instead, over the sea, the pressure forcing keeps the same positive values as in the mature phase near the surface and becomes even more negative in the upper layers, with these negative values extending well inland and thus creating a branch from the land to the sea with obvious compensatory motions at those upper levels.

Around sunset, the wind speed falls to very small values and the direction veers slowly to the opposite as the land surface cooling develops and downslope currents are created (Fig. 2). In fact, the sea-land temperature gradient reverses about $1 \mathrm{~h}$ before sunset (Fig. 5b), linked probably to the time at which the net radiation over land becomes negative. The terms of the temperature budget take values similar to the nighttime ones in the marine surface layer at 1700 UTC and over the land at 1800 UTC (Fig. 6). At sunset, turbulence stops also inland, and the PG term becomes negative (Fig. 10), implying outland flow, which marks the beginning of the nocturnal part of the cycle.

\section{Adequacy of two simple analytic breeze models}

The apparent simplicity of the SB has motivated many authors to try to describe it using simple analytical approaches, most of the time trying to oversimplify (or avoid) the treatment of the nonlinear terms. A succinct and critical historical overview of linear SB models is given by Rotunno (1983). A detailed explanation and illustration of solving a linear SB model that is based on Defant (1950) is presented by Pielke (1984); a related modified version of the same model will be developed here. On the other hand, nonlinear analytic SB models typically sacrifice some other parts of the dynamics to treat a nonlinear effect, as in, for example, Gutman (1972) or Feliks (1988). In most of those analytic SB models, the PG force induced by differential surface heating is balanced by time tendencies, linear friction (the parameterized turbulence effect), and the Coriolis effect (arguably a dispersion effect).

Here the Defant model reformulated by Pielke [Defant-Pielke Model (DPM); Pielke 1984] and the weakly nonlinear proposition of Gutman (1972) are applied to our quasi-ideal case. They are modified so as to be consistent in the treatment of the turbulence term. These models can be solved analytically under very restrictive conditions. Both models solve equations for $u, v$, and $\theta$, assuming that the phenomenon can be restricted to an $x, z$ plane. DPM equalizes the tendency of $u$ to the PG, Coriolis, and turbulence terms, and the temperature tendency is compensated by the adiabatic warming or cooling and the turbulence mixing. 
Gutman (1972) introduces an advection term for the temperature. A more extensive technical description is provided in the online supplemental material for this paper (http://dx.doi.org/10.1175/JAMC-D-14-0007.s1). For this discussion, the equations can be expressed conceptually as (different from the original propositions)

$$
\begin{aligned}
\frac{\partial u}{\partial t} & =-\frac{1}{\rho_{0}} \frac{\partial p}{\partial x}-\frac{\partial \overline{w^{\prime} u^{\prime}}}{\partial z} \quad \text { and } \\
\frac{\partial \theta}{\partial t}+w \frac{\partial \theta_{0}}{\partial z} & =-u \frac{\partial \theta}{\partial x}-\frac{\partial \overline{w^{\prime} \theta^{\prime}}}{\partial z} .
\end{aligned}
$$

DPM does not consider horizontal advection in the temperature equation and keeps an equation also for $w$, whereas the Gutman model arranges the system to avoid it. Their treatment of the turbulence term is also diverse and not coherent, since different formulations are applied for the vertical mixing and the surface forcing. Here, we apply a $K$-theory approach, imposing a slowly varying $K$ profile that is inspired by the outputs of the numerical simulations. The Coriolis term is neglected, which is consistent with the analysis of this case. Both models are fed with data from the numerical simulation ( $K$ and surface fluxes), and their outputs are inspected. The systems can be solved analytically, applying the Wentzel-Kramers-Brillouin method (Grisogono and Oerlemans 2001; Jeričević et al. 2010), with the result that the vertical variation of $K$ induces more variability in the vertical direction and a better representation of the near-surface winds than for the previous versions.

The imposed solutions are periodically varying with time (using a period of $24 \mathrm{~h}$ ) and allow the existence of a well-defined diurnal cycle and the fixing of a varying spatial forcing to mimic the effects of the sea-land discontinuity. In our case, the tendency of $u$ is proportional to the difference between the effects of the PG forcing and the turbulent mixing. Since advection is not taken into account in DPM, the model is considered to be suitable for the mature phase of the SB, when the wellestablished circulation minimizes the effect of advection at low levels. The model that is forced generates a maximum of $8 \mathrm{~m} \mathrm{~s}^{-1}$ at $100 \mathrm{~m} \mathrm{MSL}$, decreasing to zero at $400 \mathrm{~m}$ MSL, not far from what the 3D model generates (maximum of $6 \mathrm{~m} \mathrm{~s}^{-1}$ over land) but missing the nonzero wind above. DPM tendencies are compared with 3D outputs over the sea and land in Figs. 11a and 11b. The variability of the 3D models is not captured, indicating that DPM is probably too simplistic.

Gutman's (1972) proposal is a more elaborate model that introduces nonlinearity through advection in the temperature equation, which should be adequate for the processes near the coast, where the thermal gradients are most intense, and during the initial and developing phases of the SB. The system manages to transport the effect of the thermal gradient to the PG and generates the onset of the SB through the increase of wind speed. The latter is slowed down by the turbulence mixing, as in DPM. Solutions imposing a vertical decay and periodic in time are used, and the use of a mixing coefficient that varies with $z$, denoted as $K(z)$, allows for more diffused and distorted fields than does the original proposition. Figures $11 \mathrm{c}$ and $11 \mathrm{~d}$ show the tendencies over the land and over the sea close to the coastline. They are positive and nearly constant during this period and compare well for the lowest $100 \mathrm{~m}$ to those provided by the 3D model, failing to generate values above it. Farther inland, the tendencies of the Gutman model get larger than the ones provided by the 3D model, making the SB progress faster inland than in the 3D model. The performance of the Gutman model in the SB development is satisfactory near the coast if adequate input is provided. Again, the use of turbulence as a surrogate for all other processes, in particular momentum advection, may explain the differences that arise and amplify with time.

\section{Conclusions}

A successful simulation of an observed case of SB for the island of Mallorca has been analyzed. It provides results that are very close to an ideal case for the island made by RR95 and to existing climatological knowledge. Over the northern and southwestern basins, a symmetrical SB system is found, with convergence on the center of the island and signs of return flow above. Instead, the southeast-northeast line displays an asymmetrical system, with the SB from the southeast penetrating farther north because of the island's topographical configuration, and no return current is visible. The breeze in the southeastern basin is the strongest of the island and lasts longer than those of the other basins.

The analysis of the flow evolution on the southeastern basin is performed, making use of the momentum, temperature, and momentum budgets diagnosed from the model. It indicates that the SB penetrates inland after a period of land surface warming that first destroys the nocturnal inversion and afterward creates a convective boundary layer that finally is able to generate the necessary PG force, producing the inflow. The SB front travels at a speed of about $3 \mathrm{~m} \mathrm{~s}^{-1}$, and the SB remains during the rest of the daytime, with surface-layer winds close to $5 \mathrm{~m} \mathrm{~s}^{-1}$. The SB below $200 \mathrm{~m} \mathrm{MSL}$ results essentially from the equilibrium between the PG and the turbulence, with both decreasing in intensity during the afternoon. In the layers above, the pressure gradient is compensated by advective motions. This evolution has been conceptually 
(a)

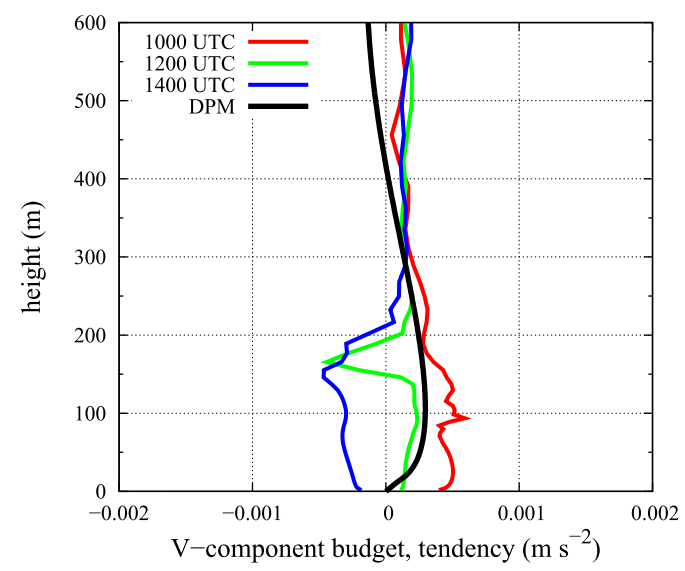

(c)

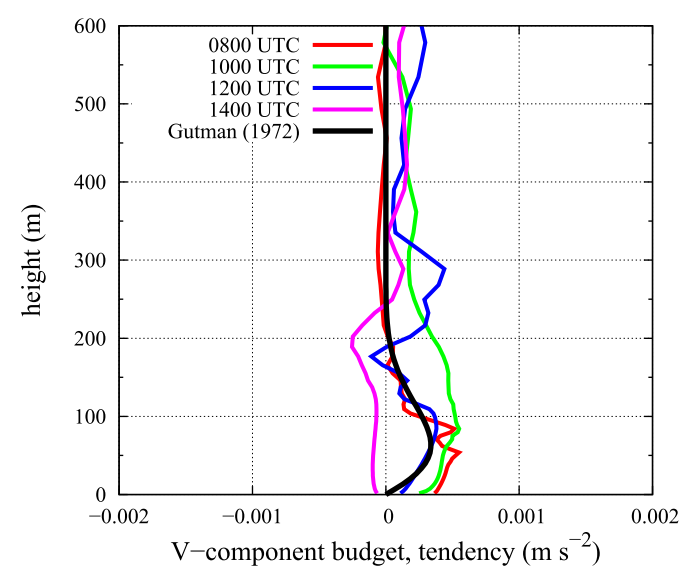

(b)

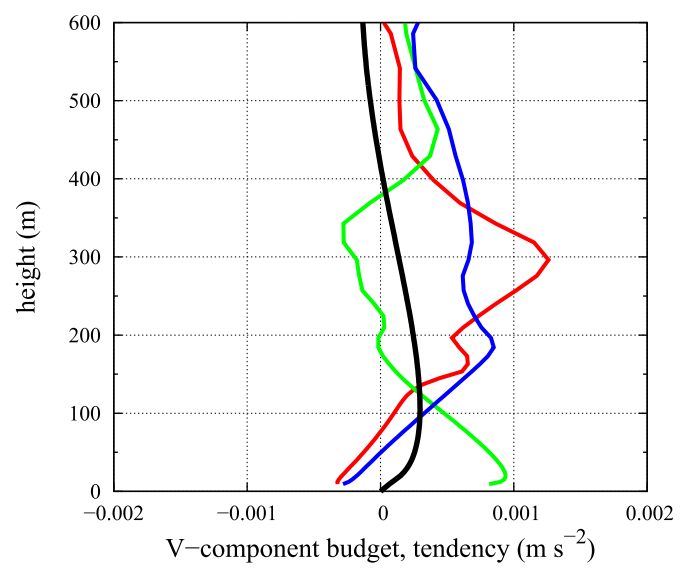

(d)

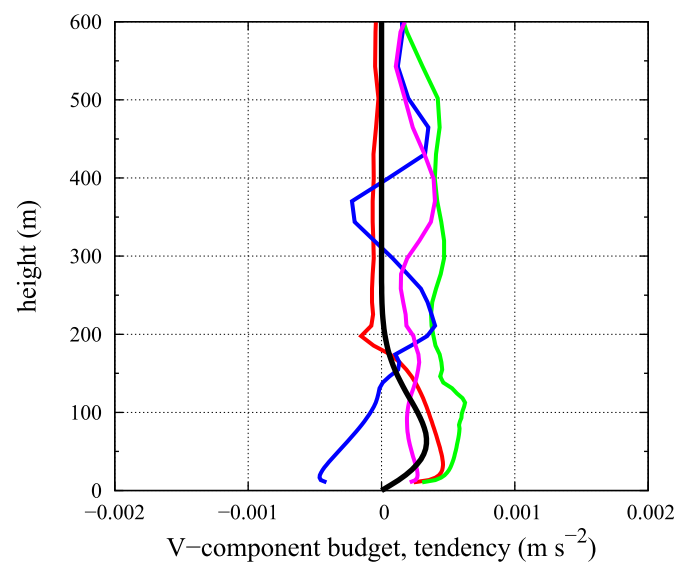

FIG. 11. Comparison of the tendency profiles of the momentum budget equation computed from the DPM with the Méso-NH simulation profiles at different instants for points (a) over the sea (position $15 \mathrm{~km}$ in Fig. 5a) and (b) over the land (position $25 \mathrm{~km}$ in Fig. 5a). (c),(d) As in (a) and (b), but for the Gutman (1972) model results.

described in five phases, going from the previous phase to the decay phase.

The size and topography of the island produce some singularities with respect to larger islands or regular continental coastlines. There is no evidence of Coriolis turning in the wind direction evolution, and its effect in the momentum budget is very small, a fact that is assumed to be caused by the effect of the slopes in the basins that determine the prevailing inflow direction. The mature stage takes place earlier than in the continent too, probably because of flow convergence in the center of the island. This real case also shows that the spatial distribution of the surface latent and sensible heat fluxes is very heterogeneous, and this is a factor that introduces complexity in the analysis of the detailed evolution of the SB.

The performance of two relatively simple analytical models (upgraded in their turbulence term) with this case is inspected. The extended Defant model, essentially considering PG and turbulence, is suitable for the mature phase, whereas Gutman's model, which includes an advection term in the temperature equation, is acceptable near the coast and in the development phase. For these phases, the models provide qualitatively satisfactory outputs, thus aiding the SB interpretation, but they miss most of the time-space variability that a full 3D nonhydrostatic model provides.

Acknowledgments. This work was partially funded by grants from the Spanish government (CGL2009-12797C03-01 and CGL2012-37416-C04-01), supplemented with FEDER funds, the project BORA 119-1193086-1311 of the Croatian Ministry of Science, Education and Sports. Author M. A. Jiménez acknowledges financial support from the JAE-Doc Programme (CSIC, cofunded by FSE). Data from the automatic weather stations have been provided by AEMET. Computing time has been 
provided by the European Centre for Medium-Range Weather Forecasts through the special project "Atmospheric Boundary Layer Processes in Complex Terrain."

\section{REFERENCES}

Antonelli, M., and R. Rotunno, 2007: Large-eddy simulation of the onset of the sea breeze. J. Atmos. Sci., 64, 4445-4457, doi:10.1175/2007JAS2261.1.

Azorin-Molina, C., B. H. Connell, and R. Baena-Calatrava, 2009: Seabreeze convergence zones from AVHRR over the Iberian Mediterranean area and the Isle of Mallorca, Spain. J. Appl. Meteor. Climatol., 48, 2069-2085, doi:10.1175/2009JAMC2141.1.

Bastin, S., P. Drobinski, A. Dabas, P. Delville, O. Reitebuch, and C. Werner, 2005: Impact of the Rhône and Durance valleys on sea-breeze circulation in the Marseille area. Atmos. Res., 74, 303-328, doi:10.1016/j.atmosres.2004.04.014.

Beare, R. J., and Coauthors, 2006: An intercomparison of largeeddy simulations of the stable boundary layer. Bound.-Layer Meteor., 118, 247-272, doi:10.1007/s10546-004-2820-6.

Belamari, S., 2005: Report on uncertainty estimates of an optimal bulk formulation for surface turbulent fluxes. Marine Environment and Security for the European Area Integrated Project (MERSEA IP) Deliverable D.4.1.2, 29 pp.

Bougeault, P., and P. Lacarrère, 1989: Parameterization of orography-induced turbulence in a mesobeta-scale model. Mon. Wea. Rev., 117, 1872-1890, doi:10.1175/1520-0493(1989)117<1872: POOITI $>2.0 . C O ; 2$.

Bryan, G. H., J. C. Wyngaard, and J. M. Fritsch, 2003: Resolution requirements for the simulation of deep moist convection. Mon. Wea. Rev., 131, 2394-2415, doi:10.1175/1520-0493(2003)131<2394: RRFTSO $>2.0 . \mathrm{CO} ; 2$.

Crosman, E. T., and J. D. Horel, 2010: Sea and lake breezes: A review of numerical studies. Bound.-Layer Meteor., 137, 1-29, doi:10.1007/s10546-010-9517-9.

$\ldots$, and — 2012: Idealized large-eddy simulations of sea and lake breezes: Sensitivity to lake diameter, heat flux and stability. Bound.-Layer Meteor., 144, 309-328, doi:10.1007/ s10546-012-9721-x.

Cuxart, J., and M. A. Jiménez, 2007: Mixing processes in a nocturnal low-level jet: An LES study. J. Atmos. Sci., 64, 1666-1679, doi:10.1175/JAS3903.1.

$\longrightarrow$, and -2012 : Deep radiation fog in a wide closed valley: Study by numerical modeling and remote sensing. Pure Appl. Geophys., 169, 911-926, doi:10.1007/s00024-011-0365-4.

_, P. Bougeault, and J.-L. Redelsperger, 2000: A turbulence scheme allowing for mesoscale and large-eddy simulations. Quart. J. Roy. Meteor. Soc., 126, 1-30, doi:10.1002/qj.49712656202.

—, and Coauthors, 2006: Single-column model intercomparison for a stably stratified atmospheric boundary layer. Bound.Layer Meteor., 118, 273-303, doi:10.1007/s10546-005-3780-1.

_- M. A. Jiménez, and D. Martínez, 2007: Nocturnal meso-beta basin and katabatic flows on a midlatitude island. Mon. Wea. Rev., 135, 918-932, doi:10.1175/MWR3329.1.

Darby, L. S., R. M. Banta, and R. A. Pielke, 2002: Comparisons between mesoscale model terrain sensitivity studies and Doppler lidar measurements of the sea breeze at Monterey Bay. Mon. Wea. Rev., 130, 2813-2838, doi:10.1175/1520-0493(2002)130<2813: CBMMTS $>2.0 . \mathrm{CO} ; 2$.

Defant, F., 1950: Theorie der Land- und Seewinde (Theory of the land and sea breezes). Arch. Meteor. Geophys. Bioklimatol., 2A, 404-425, doi:10.1007/BF02247322.
Drobinski, P., R. Rotunno, and T. Dubos, 2011: Linear theory of the sea breeze in a thermal wind. Quart. J. Roy. Meteor. Soc., 137, 1602-1609, doi:10.1002/qj.847.

Durran, D. R., 1989: Improving the anelastic approximation. J. Atmos. Sci., 46, 1453-1461, doi:10.1175/1520-0469(1989)046<1453: ITAA $>2.0 . \mathrm{CO} ; 2$.

Feliks, Y., 1988: The sea-breeze front analytical model. J. Atmos. Sci., 45, 1030-1038, doi:10.1175/1520-0469(1988)045<1030: TSBFAM $>2.0 . \mathrm{CO} ; 2$.

Finkele, K., J. M. Hacker, H. Kraus, and R. A. D. Byron-Scott, 1995: A complete sea-breeze circulation cell derived from aircraft observations. Bound.-Layer Meteor., 73, 299-317, doi:10.1007/BF00711261.

Fock, B. H., and K. H. Schlünzen, 2012: Characterization of typical coastal circulations with high-resolution measurements in the Gulf of Valencia. Int. J. Climatol., 32, 1392-1405, doi:10.1002/ joc. 2362.

Fouquart, Y., and B. Bonnel, 1980: Computations of solar heating of the earth's atmosphere: A new parametrization. Beitr. Phys. Atmos., 53, 35-62.

Grisogono, B., and J. Oerlemans, 2001: Katabatic flow: Analytic solution for gradually varying eddy diffusivities. J. Atmos. Sci., 58, 3349-3354, doi:10.1175/1520-0469(2001)058<3349: $\mathrm{KFASFG}>2.0 . \mathrm{CO} ; 2$.

_ _ L. Ström, and M. Tjernström, 1998: Small-scale variability in the coastal atmospheric boundary layer. Bound.-Layer Meteor., 88, 23-46, doi:10.1023/A:1000933822432.

Gutman, L. N., 1972: Introduction to the Nonlinear Theory of Mesoscale Meteorological Processes. Keter Press, 224 pp.

Hernández-Ceballos, M. A., J. A. Adame, J. P. Bolívar, and B. A. De la Morena, 2013: A mesoscale simulation of coastal circulation in the Guadalquivir valley (southwestern Iberian Peninsula) using the WRF-ARW model. Atmos. Res., 124, 120, doi:10.1016/j.atmosres.2012.12.002.

Holland, G. J., and J. L. McBride, 1989: Quasi-trajectory analysis of a sea-breeze front. Quart. J. Roy. Meteor. Soc., 115, 571-580, doi:10.1002/qj.49711548708.

Honnert, R., V. Masson, and F. Couvreux, 2011: A diagnostic for evaluating the representation of turbulence in atmospheric models at the kilometric scale. J. Atmos. Sci., 68, 3112-3131, doi:10.1175/JAS-D-11-061.1.

Jansà, J. M., and E. Jaume, 1946: The sea breeze regime in the Mallorca island (in Spanish). Rev. Geofis., 19, 304-328.

Jeričević, A., L. Kraljević, B. Grisogono, H. Fagerli, and Ž. Večenaj, 2010: Parameterization of vertical diffusion and the atmospheric boundary layer height determination in the EMEP model. Atmos. Chem. Phys., 10, 341-364, doi:10.5194/ acp-10-341-2010.

Jiang, Q., 2012: A linear theory of three-dimensional landsea breezes. J. Atmos. Sci., 69, 1890-1909, doi:10.1175/ JAS-D-11-0137.1.

Jiménez, M. A., and J. Cuxart, 2005: Large-eddy simulations of the stable boundary layer using the standard Kolmogorov theory: Range of applicability. Bound.-Layer Meteor., 115, 241-261, doi:10.1007/s10546-004-3470-4.

— A. Mira, J. Cuxart, A. Luque, S. Alonso, and J. A. Guijarro, 2008: Verification of a clear-sky mesoscale simulation using satellite-derived surface temperatures. Mon. Wea. Rev., 136, 5148-5161, doi:10.1175/2008MWR2461.1.

Kala, J., T. J. Lyons, D. J. Abbs, and U. S. Nair, 2010: Numerical simulations of the impacts of land-cover change on a southern sea breeze in south-west Western Australia. Bound.-Layer Meteor., 135, 485-503, doi:10.1007/s10546-010-9486-z. 
Kottmeier, C., P. Palacio-Sese, N. Kalthoff, U. Corsmeier, and F. Fiedler, 2000: Sea breezes and coastal jets in southeastern Spain. Int. J. Climatol., 20, 1791-1808, doi:10.1002/ 1097-0088(20001130)20:14<1791::AID-JOC574>3.0.CO;2-I.

Kozo, T. L., 1982: An observational study of sea breezes along the Alaskan Beaufort Sea coast: Part I. J. Appl. Meteor., 21, 891-905, doi:10.1175/1520-0450(1982)021<0891:AOSOSB > 2.0.CO;2.

Lafore, J. P., and Coauthors, 1998: The Meso-NH atmospheric simulation system. Part I: Adiabatic formulation and control simulations. Ann. Geophys., 16, 90-109, doi:10.1007/ s00585-997-0090-6.

Mahrer, Y., and M. Segal, 1985: On the effects of islands' geometry and size on inducing sea breeze circulation. Mon. Wea. Rev., 113, 170174, doi:10.1175/1520-0493(1985)113<0170:OTEOIG >2.0.CO;2.

Martínez, D., M. A. Jiménez, J. Cuxart, and L. Mahrt, 2010: Heterogeneous nocturnal cooling in a large basin under very stable conditions. Bound.-Layer Meteor., 137, 97-113, doi:10.1007/s10546-010-9522-z.

Masson, V., 2000: A physically-based scheme for the urban energy budget in atmospheric models. Bound.-Layer Meteor., 94, 357-397, doi:10.1023/A:1002463829265.

_- J.-L. Champeaux, F. Chauvin, C. Meriguet, and R. Lacaze, 2003: A global database of land surface parameters at $1-\mathrm{km}$ resolution for use in meteorological and climate models. J. Climate, 16, 1261-1282, doi:10.1175/1520-0442-16.9.1261.

Millán, M. M., R. Salvador, E. Mantilla, and G. Kallos, 1997: Photooxidant dynamics in the Mediterranean basin in summer: Results from European research projects. J. Geophys. Res., 102, 8811-8827, doi:10.1029/96JD03610.

Miller, S. T. K., B. D. Keim, R. W. Talbot, and H. Mao, 2003: Sea breeze: Structure, forecasting, and impacts. Rev. Geophys., 41, 1011, doi:10.1029/2003RG000124.

Mlawer, E. J., S. J. Taubman, P. D. Brown, M. J. Iacono, and S. A. Clough, 1997: Radiative transfer for inhomogeneous atmospheres: RRTM, a validated correlated- $k$ model for the longwave. J. Geophys. Res., 102, 16663-16682, doi:10.1029/ 97JD00237.

Morcrette, J.-J., 1990: Impact of changes to the radiation transfer parameterizations plus cloud optical properties in the ECMWF model. Mon. Wea. Rev., 118, 847-873, doi:10.1175/ 1520-0493(1990)118<0847:IOCTTR > 2.0.CO;2.

Navascués, B., and Coauthors, 2013: Long-term verification of HIRLAM and ECMWF forecasts over southern Europe: History and perspectives of numerical weather prediction at AEMET. Atmos. Res., 125-126, 20-33, doi:10.1016/ j.atmosres.2013.01.010.

Noilhan, J., and S. Planton, 1989: A simple parameterization of land surface processes for meteorological models. Mon. Wea. Rev., 117, 536-549, doi:10.1175/1520-0493(1989)117<0536: ASPOLS $>2.0$.CO;2.

Ohashi, Y., and H. Kida, 2002: Local circulations developed in the vicinity of both coastal and inland urban areas: A numerical study with a mesoscale atmospheric model. J. Appl. Meteor., 41, 30-45, doi:10.1175/1520-0450(2002)041<0030:LCDITV>2.0.CO;2.

Pielke, R. A., 1984: Mesoscale Meteorological Modeling. Academic Press, 612 pp.
Prtenjak, M. T., and B. Grisogono, 2002: Idealised numerical simulations of diurnal sea breeze characteristics over a step change in roughness. Meteor. Z., 11, 345-360, doi:10.1127/ 0941-2948/2002/0011-0345

, - — , and T. Nitis, 2006: Shallow mesoscale flows at the northeastern Adriatic coast. Quart. J. Roy. Meteor. Soc., 132, $2191-$ 2216, doi:10.1256/qj.05.41.

—, Z. Pasarić, M. Orlić, and B. Grisogono, 2008: Rotation of sea/ land breezes along the northeastern Adriatic coast. Ann. Geophys., 26, 1711-1724, doi:10.5194/angeo-26-1711-2008.

Qian, T., C. C. Epifanio, and F. Zhang, 2012: Topographic effects on the tropical land and sea breeze. J. Atmos. Sci., 69, 130-149, doi:10.1175/JAS-D-11-011.1.

Ramis, C., and R. Romero, 1995: A first numerical simulation of the development and structure of the sea breeze on the island of Mallorca. Ann. Geophys., 13, 981-994, doi:10.1007/ s00585-995-0981-3.

_ _, A. Jansà, and S. Alonso, 1990: Sea breeze in Mallorca. A numerical study. Meteor. Atmos. Phys., 42, 249-258, doi:10.1007/BF01314828.

Reuter, H. I., A. Nelson, and A. Jarvis, 2007: An evaluation of voidfilling interpolation methods for SRTM data. Int. J. Geogr. Inf. Sci., 21, 983-1008, doi:10.1080/13658810601169899.

Robinson, F. J., M.-D. Patterson, and S. C. Sherwood, 2013: A numerical modeling study of the propagation of idealized seabreeze density currents. J. Atmos. Sci., 70, 653-668, doi:10.1175/ JAS-D-12-0113.1.

Romero, R., and C. Ramis, 1996: A numerical study of the transport and diffusion of coastal pollutants during the breeze cycle in the island of Mallorca. Ann. Geophys., 14, 351-363, doi:10.1007/ s00585-996-0351-9.

Rotunno, R., 1983: On the linear theory of the land and sea breeze. $J$. Atmos. Sci., 40, 1999-2009, doi:10.1175/1520-0469(1983)040<1999: OTLTOT>2.0.CO;2.

Sakazaki, T., and M. Fujiwara, 2008: Diurnal variations in summertime surface wind upon Japanese plains: Hodograph rotation and its dynamics. J. Meteor. Soc. Japan, 86, 787-803, doi:10.2151/jmsj.86.787.

Savijarvi, H., 1985: The sea breeze and urban heat island circulation in a numerical model. Geophysica, 21, 115-126.

Seity, Y., P. Brousseau, S. Malardel, G. Hello, P. Bénard, F. Bouttier, C. Lac, and V. Masson, 2011: The AROMEFrance convective-scale operational model. Mon. Wea. Rev., 139, 976-991, doi:10.1175/2010MWR3425.1.

Simpson, J. E., and R. E. Britter, 1980: A laboratory model of an atmospheric mesofront. Quart. J. Roy. Meteor. Soc., 106, 485500, doi:10.1002/qj.49710644907.

Steele, C. J., S. R. Dorling, R. von Glasow, and J. Bacon, 2013: Idealized WRF Model sensitivity simulations of sea breeze types and their effects on offshore windfields. Atmos. Chem. Phys., 13, 443-461, doi:10.5194/acp-13-443-2013.

Talbot, C., P. Augustin, C. Leroy, V. Willart, H. Delbarre, and G. Khomenko, 2007: Impact of a sea breeze on the boundarylayer dynamics and the atmospheric stratification in a coastal area of the North Sea. Bound.-Layer Meteor., 125, 133-154, doi:10.1007/s10546-007-9185-6. 
Copyright of Journal of Applied Meteorology \& Climatology is the property of American Meteorological Society and its content may not be copied or emailed to multiple sites or posted to a listserv without the copyright holder's express written permission. However, users may print, download, or email articles for individual use. 